(C) 2016. This manuscript version is made available under the CC-BY-NC-ND 4.0 license http:// creativecommons.org/licenses/by-nc-nd/4.0/

\title{
TITLE: EVALUATING THE INCIDENCE OF HYDROLOGICAL PROCESSES DURING SITE FORMATION THROUGH ORIENTATION ANALYSIS. A CASE STUDY OF THE MIDDLE PALAEOLITHIC LAKELAND SITE OF NEUMARK-NORD 2 (GERMANY).
}

\section{AUTHORS: ALEJANDRO GARCÍA-MORENO*, GEOFF M. SMITH, LUTZ KINDLER, EDUARD POP, WIL ROEBROEKS, SABINE GAUDZINSKI-WINDHEUSER, VICTOR KLINKENBERG}

* corresponding author: garcia@rgzm.de

\begin{abstract}
Lacustrine localities were attractive environments for Palaeolithic hominins, since they provide a large and broad spectrum of resources. Moreover, they are excellent archives that allow for high-resolution environmental, chronological and archaeological analyses. However, these deposits are often subject to complex formation and post-depositional factors, including waterrelated processes. Evaluating the influence of hydrological processes in site formation is thus essential to more accurately reconstruct the duration, intensity and types of hominin behaviour within these environments. In this paper we present the orientation analysis of archaeological material from the Last Interglacial site Neumark-Nord 2, Germany. Orientation analysis was done using GIS to calculate the orientation of artefact from digital plans of the excavation surface, which were subsequently tested using circular statistics. The results of the orientation analysis are compared with a hydrological model to check the relation between preferred orientations and reconstructed areas of water flow and accumulation. Results suggest that low-energy hydrological processes could have affected certain areas of the find-bearing deposits at Neumark-Nord 2 but, overall, there is no evidence for either high-energy hydrological processes or a significant movement of parts of the archaeological assemblage.
\end{abstract}

KEYWORDS: Middle Palaeolithic; Lacustrine sites; GIS; hydrology; Orientation analysis; site formation.

\section{INTRODUCTION}

The Eemian site of Neumark-Nord 2 (Germany) is key to understanding Neanderthal adaptations to interglacials. Forested environments, typical of warm periods, have been seen traditionally as too challenging to sustain a significant hominin presence (Gamble 1987, 1986). However, the discovery of a significant number of archaeological sites from the European plain, dating to the Last Interglacial, questioned this view, providing evidence for hominin occupation at these latitudes during temperate periods (Gaudzinski-Windheuser et al. 2014; Gaudzinski-Windheuser and Roebroeks 2011; Roebroeks et al. 1992). On the European plain, many of these sites are associated with lakes formed in postglacial basins. Lakes have usually been regarded as attractive locations for human settlement, thanks to the wide variety of resources they offer (Nicholas 1998, 2006; Cunnane and Stewart 2010; Dinnin and Van de Noort 1999). Moreover, lacustrine localities often preserve and provide high-resolution archives to study past hominin behaviour. The exceptional preservation commonly associated with these deposits allows detailed environmental, chronological and archaeological analyses (Gaudzinski-Windheuser and Kindler 2012; Van de Noort 2008).

However, open-air lacustrine sites are subject to complex formation processes, usually related to hydrological processes. The lake margins, and any archaeological material deposited there, can be 
subject to fluvial processes, such as overland flow, channel flow and wave action (Behrensmeyer 1982; Hanson 1980). Investigating site formation at and around lakeland sites is essential to more accurately reconstruct the duration and intensity of hominin activities there, and thus provide a better understanding of their adaptations within these contexts.

At Neumark-Nord 2, sedimentary and micro-morphological analyses indicate that overland flow was responsible for the basin infill (Mücher 2014; Pop et al. in press). During excavation, the presence of small channels at the site was identified (Hesse and Kindler 2014). These shallow channels or gullies were also identified in a hydrological model of the paleosurface of the main find horizon (Klinkenberg 2010). The influence of these processes may result in specific distributions, such as concentration of remains at specific locations, winnowing, size-sorting of materials and sediments or preferred orientations (Hanson 1980; Behrensmeyer 1990; Petraglia and Potts 1994; Bertran and Texier 1999). Experiments have shown that post-depositional movement due to hydrological processes might result in a patterning of the orientation of artefatcs (Bertran and Lenoble 2002, Domínguez-Rodrigo et al. 2014; Petraglia and Nash 1987). Therefore, the presence of preferential orientation within a site might be indicative of the effect of hydrological processes, such as overland flow or channel flow -among other post-depositional processes- on the distribution of an archaeological assemblage. In order to approach Neanderthal spatial behaviour at Neumark-Nord 2, the possible influence of water-related processes in the formation and post-depositional history of the deposit must be addressed.

In this paper, we evaluate the possible influence of overland flow, channel flow and wave action on the formation and post-depositional history of the main find horizon at Neumark-Nord 2, level NN2/2B through orientation analysis. The orientation of archaeological material was calculated using a Geographic Information System (GIS) and analysed using circular statistics to identify the presence of linear patterns and preferred orientations, which might be the result of hydrological processes. Artefact orientation was compared with a hydrological model showing the main areas or water flow within the site, to evaluate whether orientation patterns could be associated with hydrological processes.

\section{MATERIALS: THE ARCHAEOLOGICAL SITE OF NEUMARK-NORD 2}

The archaeological locality of Neumark-Nord is located on the North German Plain, in the federal

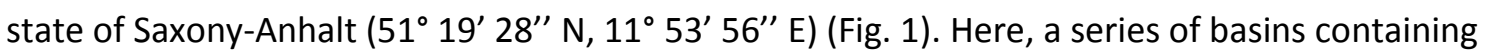
archaeological sites were exposed by mining activity (Mania and Meller 2010), and two of them, Neumark-Nord 1 (NN1) and Neumark-Nord 2 (NN2), both dating to the Last Interglacial, were excavated and systematically analysed (Gaudzinski-Windheuser and Roebroeks 2014; GaudzinskiWindheuser et al. 2014; Jurkenas et al. 2006). These basin structures were formed as a result of isostatic movements caused by lignite diapirism, and were subsequently infilled by Pleistocene sediments. Extensive mining activity in the 1980s revealed the basin structure of Neumark-Nord 1 (NN1) that was extensively excavated by D. Mania from 1985 to 1996 (Mania and Meller 2010). In that year, the new basin of Neumark-Nord 2 (NN2) was discovered, located a few hundred metres to the northeast of NN1 (Gaudzinski-Windheuser et al. 2014). Excavations took place from 2003 to 2008, the last two years in collaboration with the Landesamt für Denkmalpflege und Archäologie Sachsen-Anhalt (Germany), the MONREPOS Archaeological Research Centre and Museum for Human Behavioural Evolution of the Römisch-Germanisches Zentralmuseum Mainz (Germany) and the Faculty of Archaeology, Leiden University (The Netherlands). 


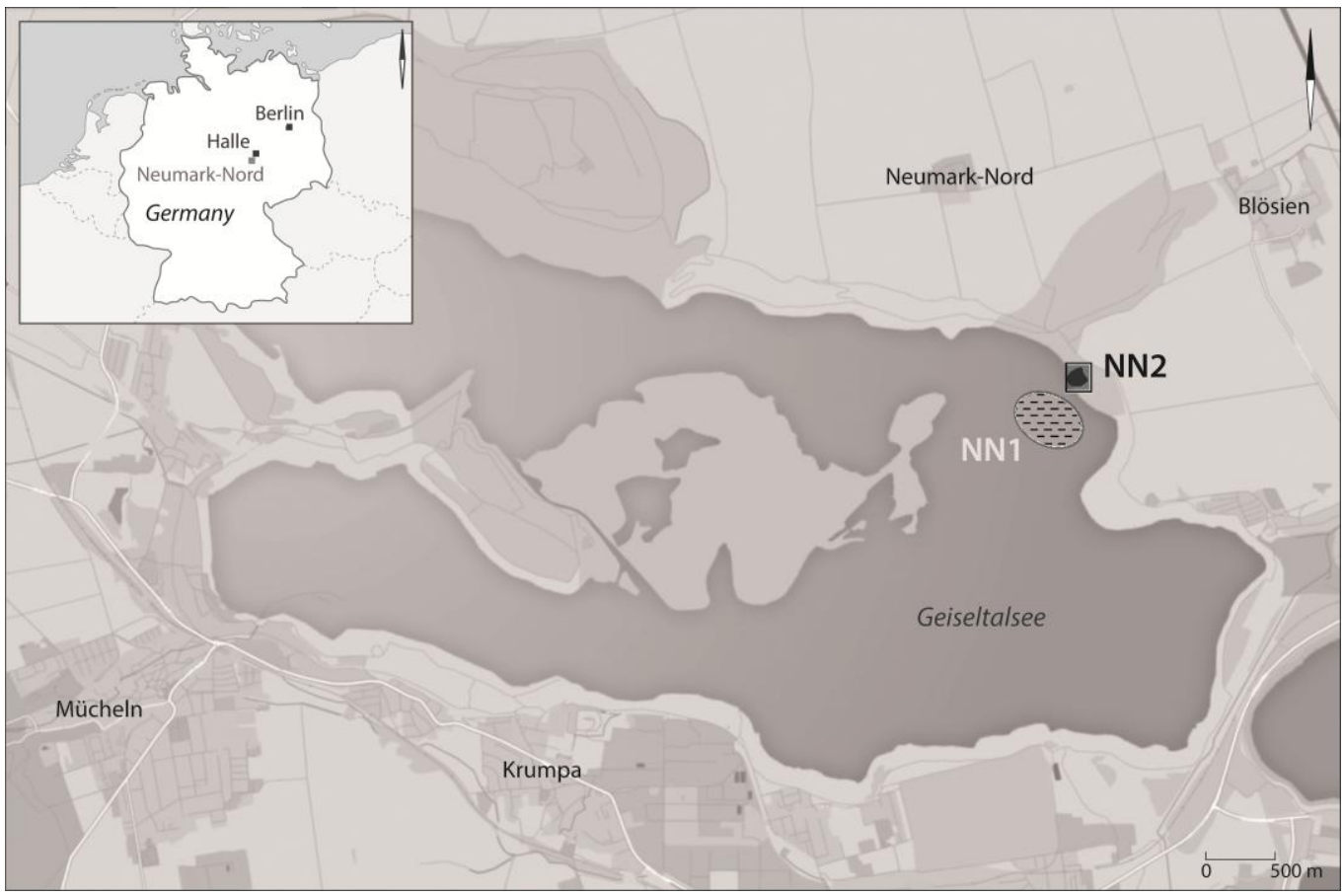

Figure 1. Location of the Neumark-Nord 2 basin within the context of modern Geiseltal lake.

The NN2 basin is formed within a Saalian sandy-gravel diamicton, and its infill is covered by ca. $6 \mathrm{~m}$ of Last Glacial (Weichselian) loess (Sier et al. 2011; Strahl et al. 2010). Palynological, malacological and micromorphological analyses suggest that within this basin a rather small pond of shallow water formed, with changing water table level with a tendency for drying up in certain seasons or over short periods (Bakels 2014; Kuijper 2014; Mücher 2014; Pop et al., 2015). Palynological analyses show a vegetational sequence typical of the Eemian (Bakels 2012, 2014), while paleo-magnetism analysis successfully identified and correlated the Blake event to NN2's palynological sequence (Sier and Deckers 2014; Sier et al. 2011). Other proxies including small mammals (Heinrich 2014) and sediment residues (Kuijper 2014) also provide evidence of temperate conditions. Stable isotopes on herbivore bulk-bone collagen indicate the existence of a biodiverse flora with evidence for vegetation patching around Neumark-Nord 2 (Britton et al. 2012; Britton et al. 2014). A series of TL dates conducted on heated flints provided a weighted average age of $126 \pm 6 \mathrm{ka}$ BP, which is consistent with an Eemian chronology (Richter and Krbetschek 2014).

The archaeological deposits consists of a series of find horizons, of which Horizon 2 (NN2/2) yielded the largest archaeological assemblage. In this horizon, around ca. 20000 lithics and ca. 120000 faunal remains were recovered in a sequence of calcareous silt loams (Hesse and Kindler 2014). Find horizon NN2/2 developed mainly at the northern margin and slope of the basin. In its northern-most part, find level NN2/2 was ca. $0.2 \mathrm{~m}$ thick, but it became more complex and thicker towards the centre of the basin, where it reached a thickness of around $1 \mathrm{~m}$ of partially laminated substrata. Due to this increasing complexity, the level NN2/2 was subdivided in three sub-layers (A, B and C), with further subdivisions within level 2/2B (Supplementary Material Figure 1) (Hesse and Kindler 2014; Jurkenas et al. 2006). 
Level NN2/2B was the richest archaeological horizon, yielding more than $90 \%$ of the threedimensionally recorded finds with the largest horizontal distribution. Two-thirds of the finds were recovered from a narrow strip located at a step within the sloping margins, situated in the centre of the excavation area. At the base of find horizon NN2/2B, archaeological material appeared clustered within a series of circular concentrations (Hesse and Kindler 2014; Jurkenas et al. 2006).

The analysis of the lithic assemblage shows that onsite knapping activities were focused on the production of large quantities of flakes (Pop 2014). Cores were worked using discoidal or more ad8 hoc reduction strategies and were intensively exploited until exhaustion. Retouched tools consist of 9 denticulates, notches and scrapers. It is likely that some flint tools (Pop 2014) were used for butchering animals, given the high incidence of cutmarks on the faunal material (Kindler et al. 2014). Among the fauna, cervids, bovids and equids are by far the most represented taxa, with a marginal presence of other species such as elephant, rhino, and carnivores (Kindler et al. 2014). Carcasses were intensively exploited by hominins, as shown by the high frequency of cut marks and impact marks from marrow extraction. Conversely, the incidence of carnivore-marks is extremely low $(<1 \%)$. Together, these factors suggest that the faunal assemblage was exclusively accumulated through Neanderthal subsistence behaviour, which involved the intensive exploitation and butchery of herbivores around the lake margins at Neumark-Nord 2 using lithic tools produced on locally available raw materials. The large archaeological assemblages from this level, accurately recorded in three-dimensions, provide an excellent dataset for the study of artefact orientation to provide a more in depth perspective on site formation and the role of Neanderthals at Neumark-Nord 2.

\section{METHODS}

\subsection{Orientation analysis}

Orientation analysis can be based on a variety of measurements. Most commonly, an artefact orientation is calculated based on its longer axis azimuthal angle in relation to a reference direction (usually geographic north), as well as artefact longer axis dip angle compared to an ideal horizontal plane (Lenoble and Bertran 2004). Therefore, this analysis requires the careful and systematic documentation of these measurements during excavation. The use of manual methods may imply a bias on the measure of orientations, due to the natural human inclination to rounding and, therefore, the application of specific methodologies to record artefact orientation is desirable (McPherron 2005).

In the case of Neumark-Nord 2, 21217 mammal bones and 9.195 lithics were documented three dimensionally in the field using a total station. Due to the time-restricted conditions of the NN2 excavation, the systematic recording of artefacts orientation was not always possible. However, in addition to three-dimensional documentation of artefact, detailed excavation plans (scale 1:10) indicating the position of artefacts were produced in the field. These plans were later accurately digitised and georeferenced at the Department of Human Origins, University of Leiden (Fig. 2). In addition to the plans, pictures of the excavation surface were taken as well. These pictures were compared with the original and digitised drawings, in order to check their accuracy (Supplementary Material Figure 2). 


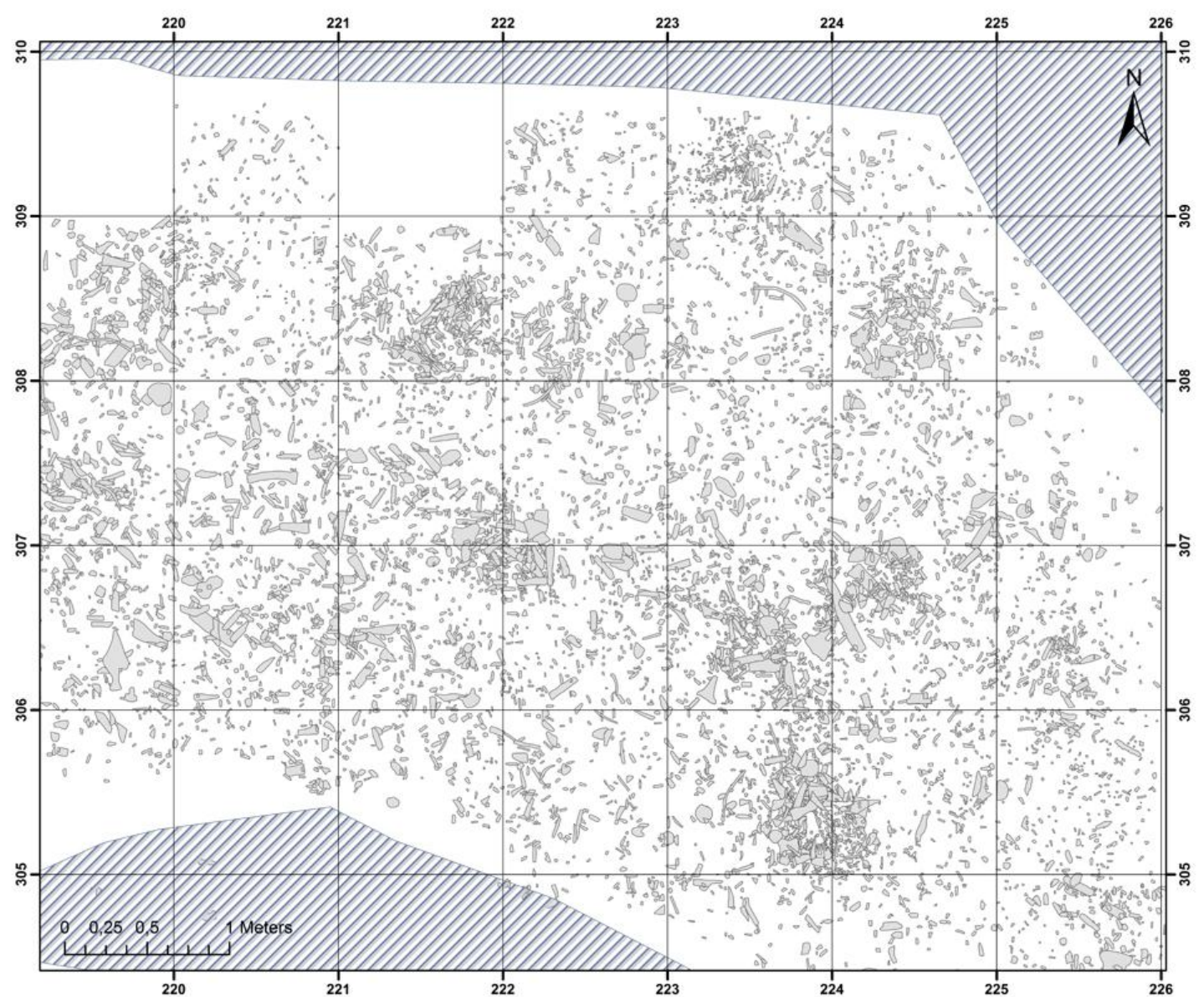

2 Figure 2. Detailed view of the vectorised plans of NN2/2B excavation surface. The artefact shape was used to calculate its longest axis indicating its orientation.

These plans make it possible to calculate artefact orientation through their shape (Benito-Calvo and de la Torre 2011). However, calculating artefacts' orientation from plans or photographs entails a series of limitations. Firstly, a plan provides only a two-dimensional perspective and thus excludes any dip angles, which makes a complete fabric analysis impossible. Secondly, the quality and accuracy of the data is largely dependent on the precision of these drawings. Furthermore, at NN2 not all squares were drawn in the field, which creates gaps in the excavation surface available for analysis.

A final limitation is related to the conceptualization of the axis representing artefact orientation. An artefact's measured orientation can change significantly depending on the axis considered and on how it is measured (Domínguez-Rodrigo and García-Pérez 2013). This problem may not be significant in the case of elongated elements, but can be an issue when dealing with amorphous or square-like artefacts (Benito-Calvo and de la Torre 2011). This is especially true when applying GIS to orientation analysis, since different methods can be used to calculate an artefact's axis from vectorised entities such as the polygons representing archaeological remains in digitalised plans (de la Torre and BenitoCalvo 2013).

In the case of Neumark-Nord 2, the determination of the orientation of finds was based on the calculation of the rectangle representing the smallest width enclosing every element. This rectangle 
was created using the Minimum Bounding Geometry tool of ArcGIS Data Management toolkit, selecting the option rectangle by width for the type of geometry (Boschian and Saccà 2010; de la Torre and Benito-Calvo 2013). This tool also allows for the calculation of the geometry characteristics for each resulting rectangle, including rectangle length, width and orientation (measured as the azimuthal angle of the longer side of that rectangle). Thus, the rectangle's length and width corresponds with the artefact's maximum length and width, while the rectangle's orientation corresponds to the artefact's longest axis orientation.

Once the minimum bounding rectangles were calculated, those measuring more than $2 \mathrm{~cm}$ and with an elongation ratio (length/width) larger than $1.6 \mathrm{~cm}$ were selected. Smaller finds were not considered, as their size is below "the minimal value for identifying a preferred orientation" (Lenoble and Bertran 2004: 458). The orientation was then obtained for the remaining artefacts. However, the sample ( $n=8873$ ) was too large for orientation analysis, since orientation statistical significance is inversely related to the number of observations ( $p$-value tends to decrease whereas $n$ increases) (Bertran and Lenoble 2002). For that reason, it was decided to do the analysis per square metre. Units with less than 40 artefacts were ignored, since smaller samples are considered unrepresentative (Bertran and Lenoble 2002). Sixty units qualified, with artefacts counts ranging from 41 to 313 artefacts. Results of the orientation data for both the entire assemblage and each unit were plotted as rose diagrams (Davis 2002; McPherron 2004).

Using Oriana 4, the mean vector of artefacts within each square metre was calculated, expressed by its direction ( $\mu$, the mean angle of artefacts) and its length ( $r$, which ranges from 0 to 1 , where values close to 1 indicate a clustered orientation around the mean angle). Mean vector also permits the calculation of some other circular statistics such as concentration $(k)$ or circular variance and standard deviation. In order to evaluate the significance the mean orientation, a Rayleigh test was conducted for each unit. Rayleigh's Uniformity Test calculates the probability that the observed distribution follows a uniform -linear- pattern (Davis 2002). If this probability is smaller than the chosen significance level ( $p$-value $<0.05$ in our case), then the alternative hypothesis stating that the sample follows a linear distribution -preferred orientation- can be accepted with confidence (BenitoCalvo and de la Torre 2011; Lenoble and Bertran 2004). However, Rayleigh's test presumes that, if preferentially oriented, the analysed sample has a single mode, and therefore it will fail in identifying non-uniform, bi-modal (or multi-modal) orientations (Davis 2002). For that reason, a Kuiper's test was also performed (Benito-Calvo and de la Torre 2011; Domínguez-Rodrigo and García-Pérez 2013).

Rayleigh's and Kuiper's p-values were given to the corresponding square within the excavation grid. This produced a vector layer for each test, where each polygon corresponded to a $1 \times 1$ square metre, and illustrating in which areas of the excavated surface artefacts showed a significant preferred orientation. Considering the corresponding mean vector and rose diagram for each unit, it was also possible to evaluate which, if any, was the dominant orientation -or orientations- of artefacts across the site.

\subsection{Hydrological model}

In order to check if any observed preferential orientations could have been related to water flow at the site, a hydrological model reconstructing the main areas of water flow was created (Boschian and Saccà 2010). In previous work, Klinkenberg (2010) modeled water motion and behaviour over a paleo surface representing the base of find horizon B. It illustrates the possible presence of gullies on 
the subsurface, but it did not evaluate where the areas of water accumulated and, in relation to the orientation analysis, it did not allow for comparisons between water flow and artefact orientations.

The basis for our hydrological model was the base of find horizon $B$, defined as the bottom of subfind horizons B3 Basis - B3 lower (Unit 8 according to Mücher's classification)(Hesse and Kindler, 2014). The base of horizon $B$ was horizontally and vertically recorded in stratigraphic profiles as well as three-dimensional points. This set of points was plotted in ArcGIS, resulting in a 1x1 metres grid. Using this grid, a Digital Elevation Model (DEM) was created using the Inverse Distance Weighted (IDW) interpolation method. This method generates a continuous surface, from a given set of points, in this case those defining the base of horizon B (Hageman and Bennett, 2000). The IDW method was chosen because it gives a higher weight to nearest points and in consequence, it was considered to represent more accurately changes along the contact between both units. Furthermore, IDW assumes that input points are regularly distributed, as was the case in our dataset. A $25 \mathrm{~cm}$ DEM was used to create the hydrological model, since that was considered the most accurate resolution (Mean Square Error $=0.035 \mathrm{~m}$ ).

Before creating the hydrological model, the DEM was analysed using ArcGIS's Sink tool, to identify possible gaps, cells where estimated flow could be directed to any adjacent cell. In order to avoid these gaps, a depressionless DEM was created using the tool Fill, which equalise those sinks with the adjacent cells and creates a paleo-surface without discontinuities along the drainage network.

The resulting DEM was then used to calculate water Flow Direction, which produces a raster layer showing the direction of water flow, based on the direction of steepest descent from each cell. Finally, the latter was used to evaluate Flow Accumulation, an estimation of where water would accumulate along the study area, based on from how many adjacent cells water would flow into each cell in the model. It is nevertheless important to keep in mind that the resulting hydrological model is based on the bottom of horizon B as documented during excavation, which may differ from its original configuration due to post-depositional processes (Hesse and Kindler 2014), such as uplifting.

\section{RESULTS}

\subsection{Orientation analysis}

For the entire NN2/2B find horizon, orientation was calculated for 8313 finds equal or larger than 2 $\mathrm{cm}$ and with an elongation index of $1.6 \mathrm{~cm}$ or higher. Mean orientation was $144.76^{\circ}$ indicating a mean NW-SE orientation (of a maximum value of $180^{\circ}$ for a N-S vector), with a standard deviation of $72.3^{\circ}$, suggesting a high variability in the sample, as observed in the rose diagram (Fig. 3 ). According to the rose diagram, north-south orientations are dominant, followed by west-east ones, which may indicate the presence of preferential orientations for part of the assemblage.

Regarding the orientation analysis of the $1 \times 1$ units, despite some containing a high number of artefacts, some of the units with the larger frequency of artefacts show high, non-significant $p$ values on the Rayleigh's test, while units with few elements show $p$-values lower than 0.001 (Supplementary material Table 1). Linear correlation analysis shows that there is no significant dependence between $p$-value and the number of elements in each unit $(r=-0.149, p=0.084)$. This suggests that orientation analysis results were not dependent on the number of artefacts in each unit. 


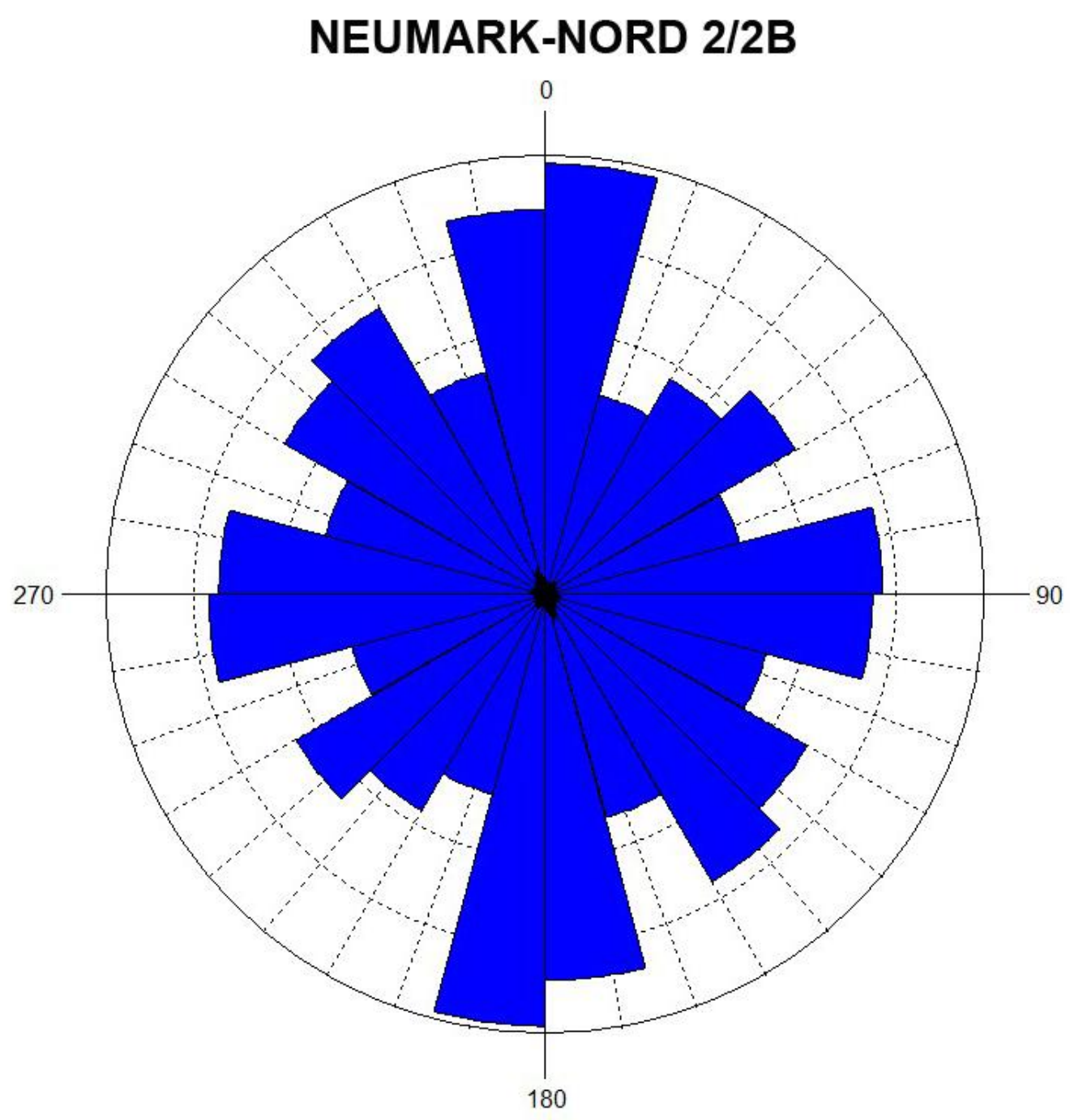

3

4 Figure 3. Rose diagram showing the orientation of Neumark-Nord 2/2B archaeological assemblage.

5 Note the high variability of artefact orientation.

7 Rayleigh's test shows that 23 out of 59 (39\%) studied units show preferred orientation and a linear pattern of the artefacts inside them (Supplementary material Table 1). The mean vector of these 23 units is $108.16^{\circ}$, although a high standard deviation of $61.05^{\circ}$ indicates the great variability in orientation. North-south mean vectors are dominant within units where finds show significant linear orientations, appearing in 14 of them (60.87\%). The great variability of mean vectors prevents any interpretation from these values, and therefore the orientation of artefacts within each unit must be analysed.

When considering the location of the 23 units with more than 40 elements showing preferred linear orientation, three main areas can be distinguished (Fig. 4 and Supplementary material Figure 3). Two 
1 of these areas ( $a$ and $b$ ) are located in the northern part of the site, separated from each other by a

2 disturbance caused by mining activity at the site. 10 out of 13 (76.92\%) of the squares analysed from 3 these northern areas show a linear orientation.

4 The third area is located in the central part of the site (Fig. 4, c), where the highest concentration of 5 archaeological material was documented. Compared to the northern part of the site (areas $a$ and $b$ ), 6 the number of units where a significant orientation was identified by the Rayleigh's test is much 7 lower, since in less than a third of this area artefacts reflect a linear pattern.

8 Considering the mean orientation of artefacts in units showing preferential orientation (Fig. 4), three 9 main directions can be observed. The most common vectors are oriented broadly north-south, while in some squares artefacts' mean orientation follows a west-east axis. This pattern, together with the presence of axial distributions observed in the rose diagrams of several $1 \times 1$ units, where -at leasttwo preferential orientations can be observed (Fig 5), may indicate the existence of bi- or multimodal distributions. In that case, the Rayleigh's test might fail in identifying preferential orientations. For that reason, a Kuiper's test was performed for each square.

The Kuiper's test for uniform distributions identifies more units where artefacts show preferential orientations than those identified by the Rayleigh's test. In this case, artefacts from 39 units (66\%) show non-uniform orientations (Fig. 6 and Supplementary Material Figure 4). This difference is due to the presence of units where artefacts follow two -or more- preferential orientations (Fig. 7). Despite the difference in the number of units showing preferential observations, the resulting pattern is similar in both cases. When analysing the distribution of units with non-uniform orientations, the three areas defined based on the Rayleigh's tests become more evident. Therefore, both Rayleigh's and Kuiper's tests identified three main areas where finds follow preferential orientations. However, the existence of units with more than one preferential orientation probably indicates that different hydrological processes might have affected the assemblage, resulting in different orientation patterns (uniform, linear and bi- or multimodal). 


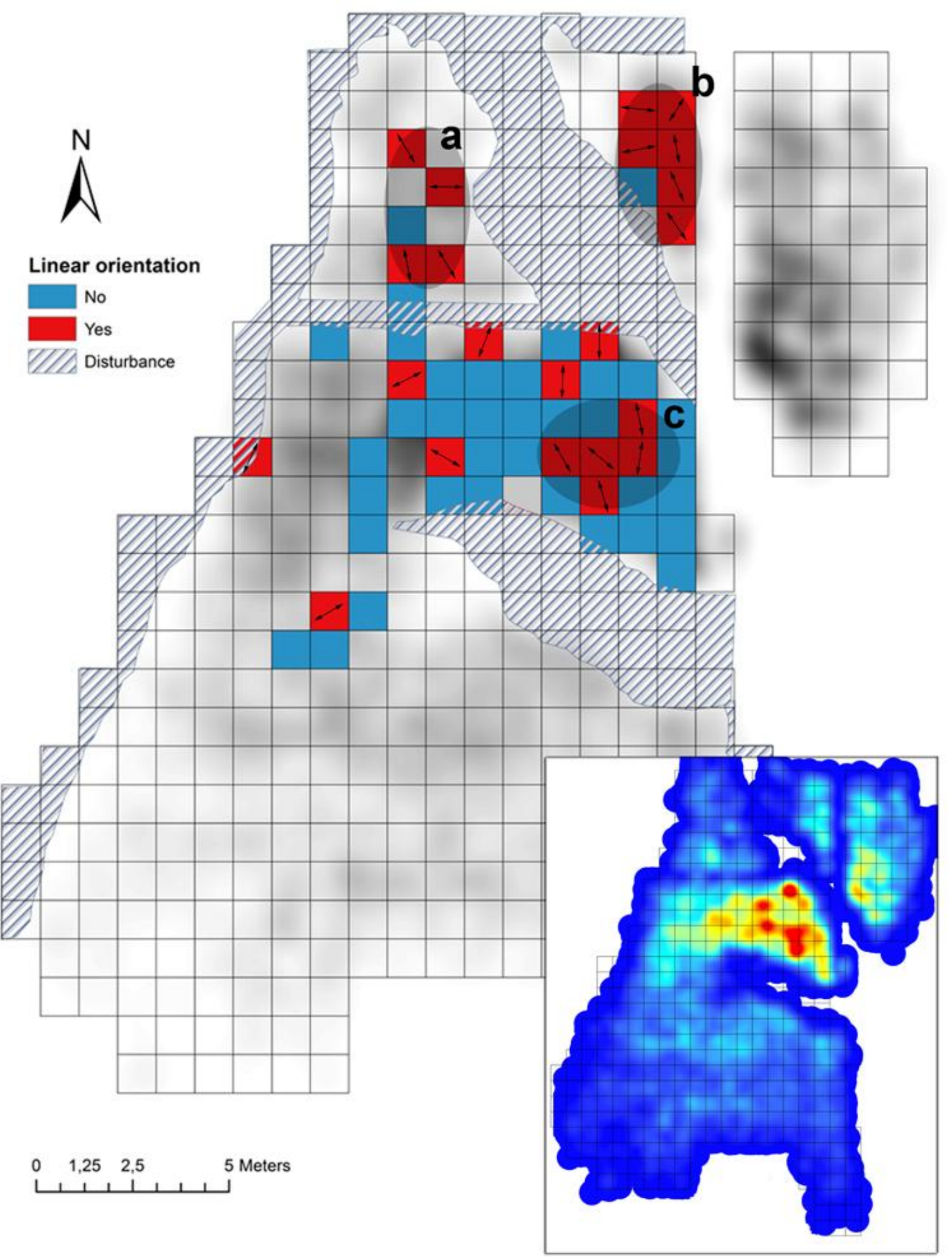

Figure 4. Orientation analysis for $1 \times 1$ units with more than 40 artefacts with the three areas mentioned in the text indicated. Red squares indicate units where artefacts show linear orientation according to Rayleigh's test, while $a, b$ and $c$ indicate the areas where these squares concentrate. Arrows in these units indicate the mean vectors. Insert: Kernel density analysis showing the main accumulation area in the centre of the site. 


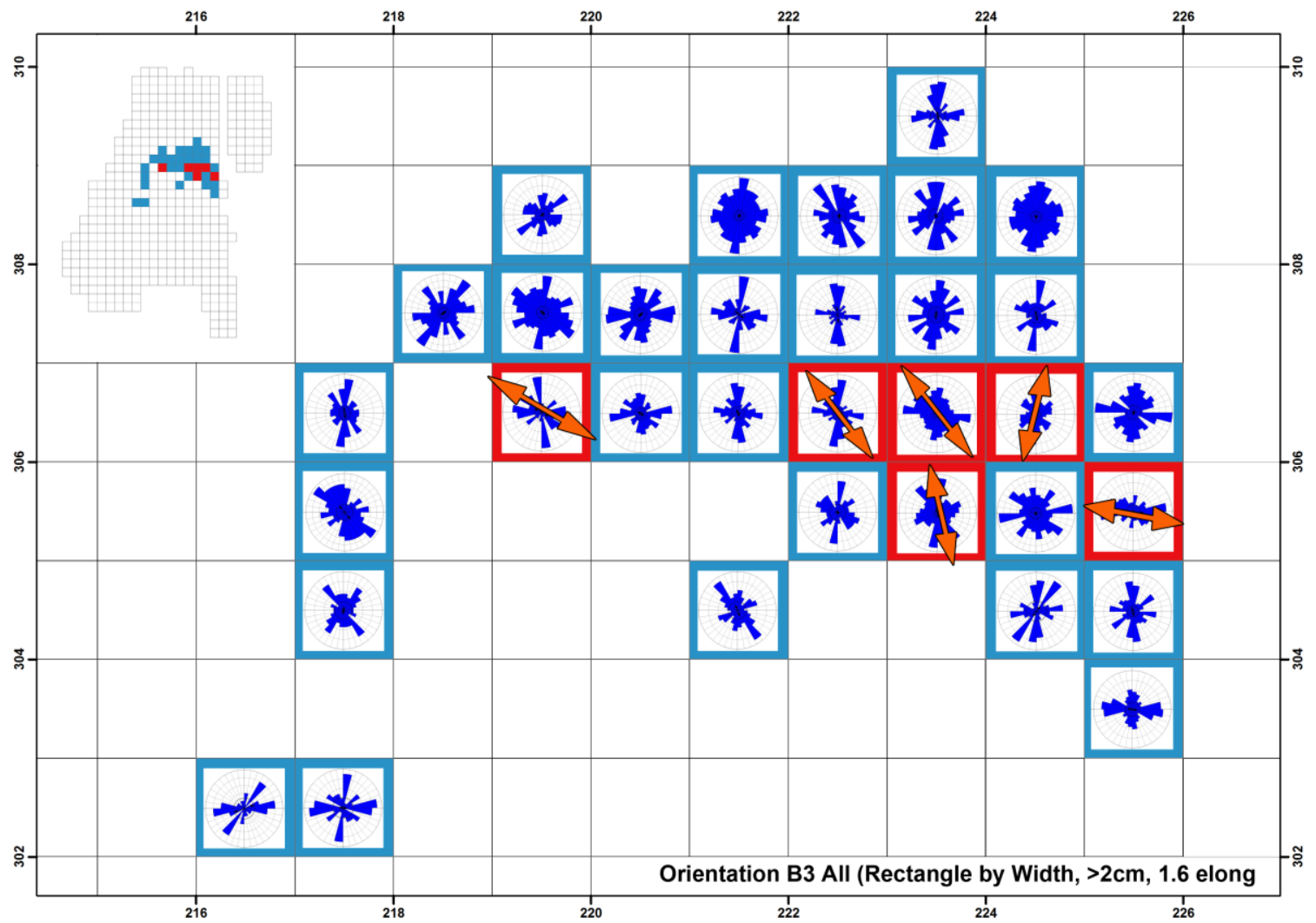

Figure 5. Detail of the orientation analysis for sub-horizon NN2/2B3, the base find horizon B, including rose diagram for each unit with more than 40 elements in it. Red outline indicates the presence of a significant linear orientation according to Rayleigh's test. Orange arrows indicate the mean vector. 


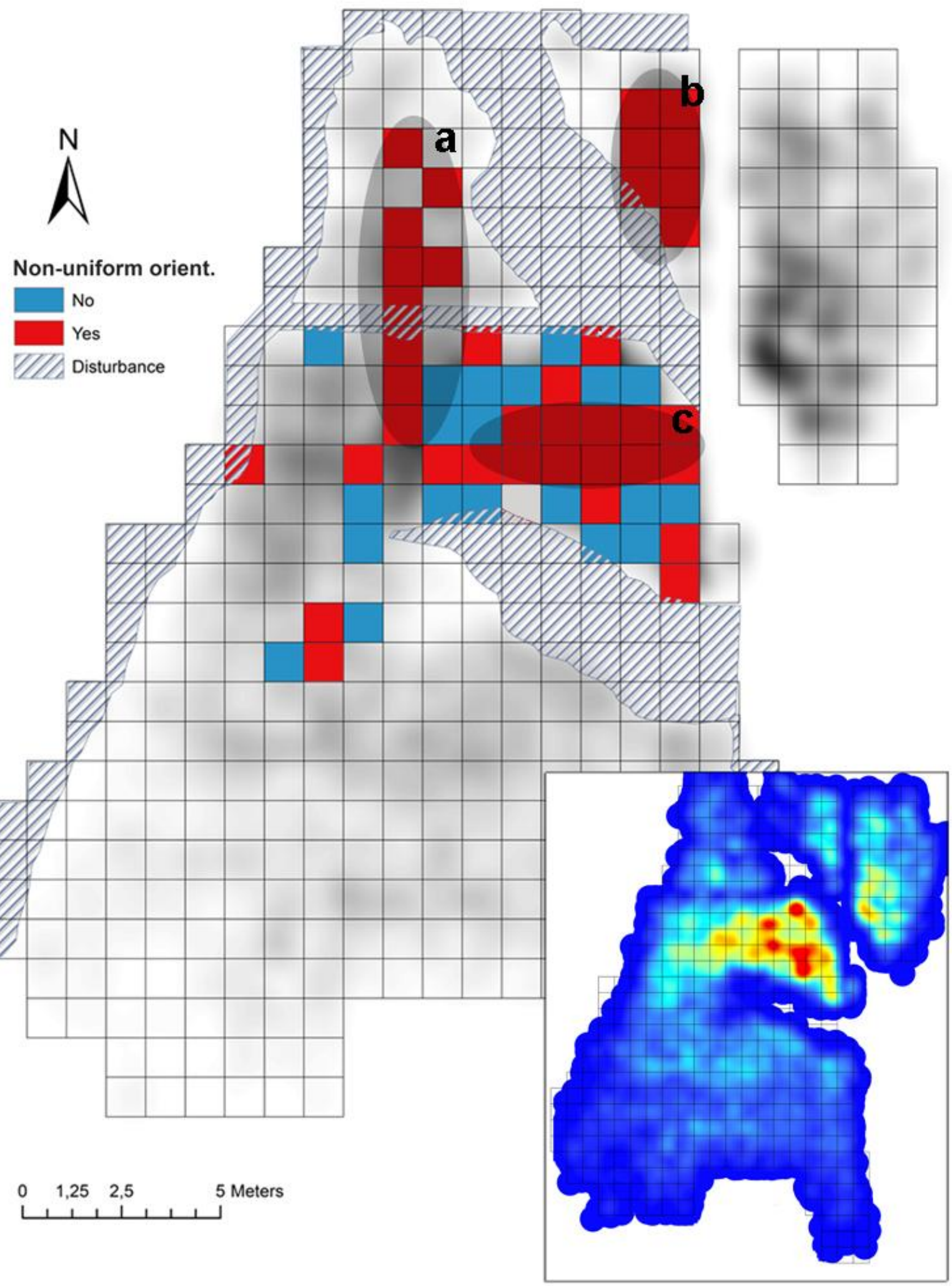

Figure 6. Orientation analysis for $1 \times 1$ units with more than 40 artefacts based on a Kuiper's test for uniform distributions. Red squares indicate units where artefacts show non-uniform (preferential) orientations. $a, b$ and $c$ indicate areas where squares showing preferential orientations concentrate. Insert: Kernel density analysis showing the main accumulation area in the centre of the site. 


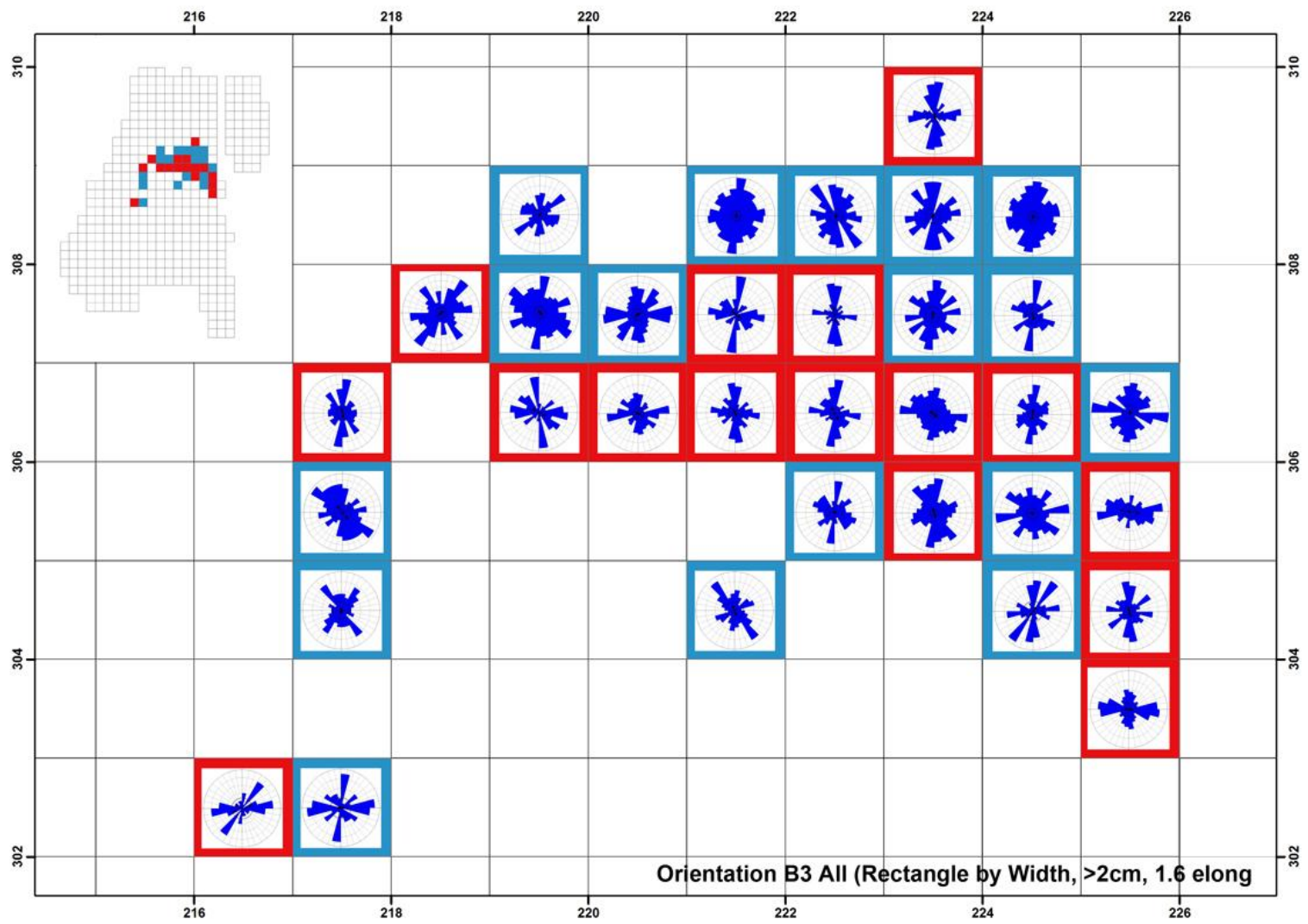

Figure 7. Orientation analysis of the base of the main find horizon B (sub-horizon B3) based on a Kuiper's test, where the red outline indicates units where finds follow a non-uniform (preferential) orientation.

\subsection{Hydrological model}

The flow accumulation model predicts two small parallel shallow channels flowing from north to south (Fig. 8); a third one can be seen flowing from west to southeast. These three main shallow channels follow the general slope of the site, flowing from the northern (higher) part of the site to the centre of the basin in the south. This model is consistent with Klinkenberg's (2010), who also recognized the presence of two "gullies" running from north to south at the same location as these channels.

Comparing the hydrological model with the orientation analysis (Fig. 8), a certain relationship between channels and squares where linear orientation was measured by the Rayleigh's test can be inferred. This correspondence is clearer on the eastern side of the central area (area $a$ in Fig. 8), where units showing linear orientations overlap with the main estimated channel, although it can also be noticed in some other regions such as the small westernmost channel in the northern area (b). A Student's t correlation test indicates a statistically significant relation ( $t=-2.658 ; p$-value $=$ 0.01 ) between the fact that units have linear distributions or not and the water accumulation value predicted by the hydrological model. This pattern is clearer when considering the results of the Kuiper's test, since the overlap between units with non-uniform orientations and areas of main water flow is higher (Supplementary Material Figure 5). Considering the orientation of mean vectors, in most of those squares mean vectors follow the same direction than the expected water flow, 
1 although in some cases they have a different orientation. This might indicate the existence of 2 different processes in the formation of the deposit.

3

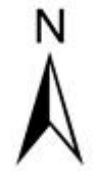

Linear orientation

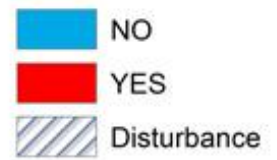

sturbance

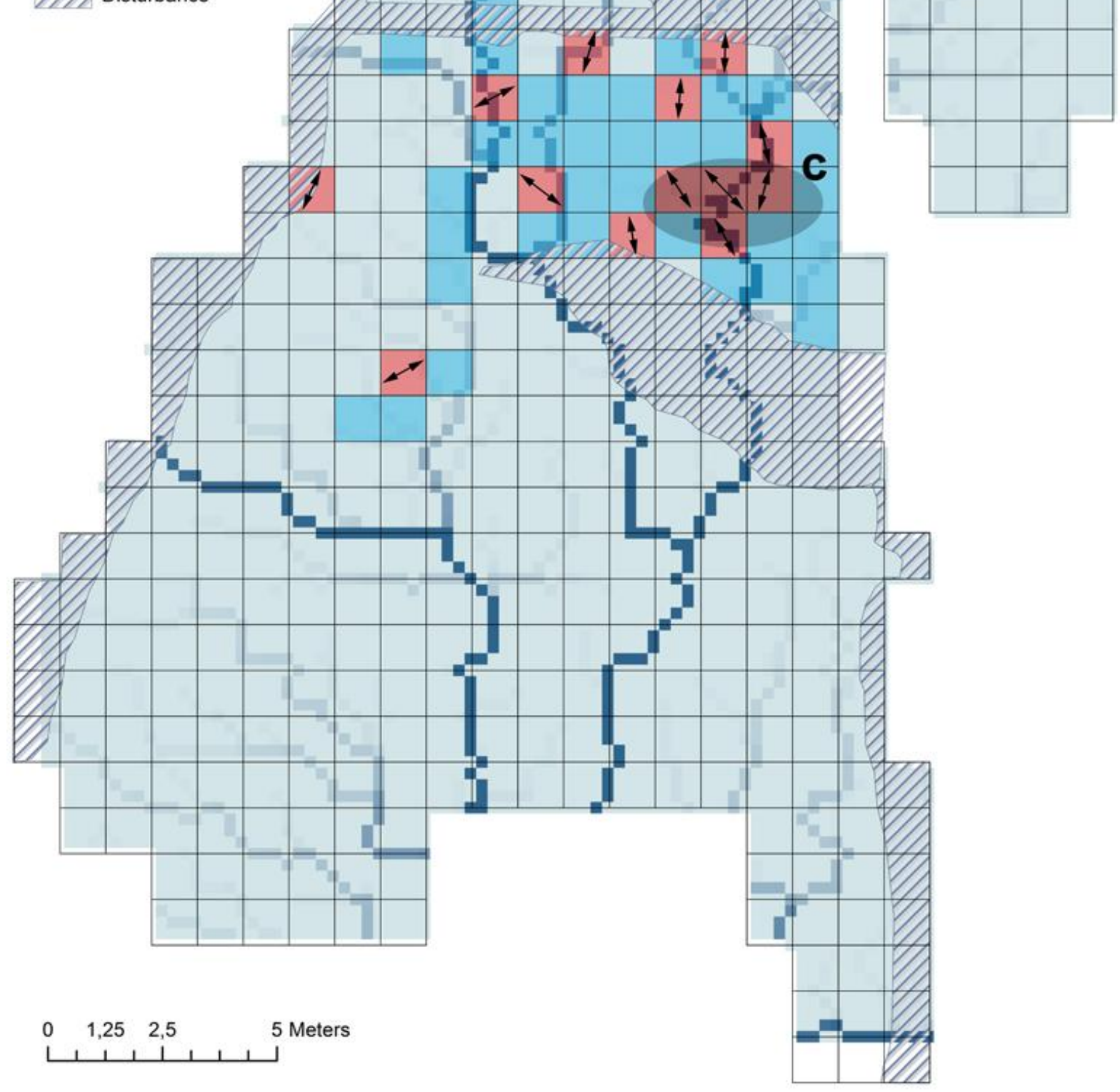


Figure 8. Hydrological model showing shallow "channels" at the base of NN2 find horizon 2B, compared to orientation of finds within units as calculated from a Rayleigh's test. Arrows indicate the mean orientation vector, while $a, b$ and $c$ indicate areas with concentration of preferential orientations.

\section{DISCUSSION AND CONCLUSIONS}

Orientation analysis of NN2/2B shows that in some areas of the site there is significant evidence for preferential orientation of the archaeological assemblage, meaning that in those units most of the artefacts share similar orientations. The presence of preferential orientations in several squares in NN2/2B may indicate some influence of hydrological processes in the formation of the site (Schiffer 1987; Petraglia and Nash 1987; Petraglia and Potts 1994), as has been proposed in previous works (Klinkenberg 2010; Hesse and Kindler 2014). However, the nature and extent of that influence could have been diverse. The presence of both linear orientations and multimodal (in some cases axial) distributions at NN2/2B, suggest that different processes were affecting the assemblage.

Two different kind of hydrological processes can be differentiated, according to their potential influence over archaeological deposits (Schick 1986; Behrensmeyer 1990). High-energy processes, which can disturb and rework a site, usually relate to major streams or "catastrophic" events where water flows in a large volume and/or with high speed. Low-energy processes can be defined as processes where a limited volume of water flows slowly, developing low kinetic energy. Their influence on the archaeological materials is limited. Moderate rainfall, overland flow, small watercourses or deposition of artefacts in shallow waters are typical examples of low-energy hydrological processes. For simplification purposes, in this work we will refer to "channels", defined here as narrow and shallow sloping depressions, formed by a limited amount of low-energy flowing water.

In the case of NN2/2B, hydrological processes seem to have affected specific areas of the deposits, as units with preferential orientations tend to concentrate in particular areas. The effect of hydrological processes might have been higher in the northern part, where most of squares show a preferential, usually linear, orientation. In contrast, in the central area there is a number of squares with uniformly orientated artefacts, suggesting that this area was not affected by high-energy processes. However, several squares in this area show multimodal orientations, and many of the finds here follow west-east, transversal-to-the-slope orientations (Fig. 9), which suggest that this area was effected somehow by post-depositional processes.

The hydrological model of water flow allows inferring some relationship between the predicted areas of water flow and areas where artefacts show preferred orientations, since many of the units showing preferred orientation overlap with areas of water flow (Fig. 8 and Supplementary Material Figure 5). In some units, the mean orientation vectors do not follow the same direction as the water flow predicted by the hydrological model, and in some cases mean vector -or one of the preferred orientations in units with bimodal distributions- is perpendicular to the water flow. This pattern suggests that hydrological processes may have affected to a certain degree the archaeozoological assemblage, mainly in specific areas of the site.

Different lines of evidence, such as sedimentology, taphonomy, and the preservation and the spatial distribution of the assemblage, suggest that high-energy formation and post-depositional processes did not affect the deposit. Sedimentological and micromorphological analyses indicate that find level 
was exposed to net deposition, suggesting a rapid, near continuous infill of the basin mainly by overland flow (Mücher 2014; Pop et al., 2015). The sedimentary context of the find horizons - silt loams- and the presence of laminated layers (Hesse and Kindler 2014) indicate low-energy deposition. Limited uplifting and/or subsidence could also have taken part in the post-depositional history of the deposit. These processes can result in transport or reorientation of finds, due to changes in the slope or aspect at some places, but their effect on the assemblage would have been minimal.

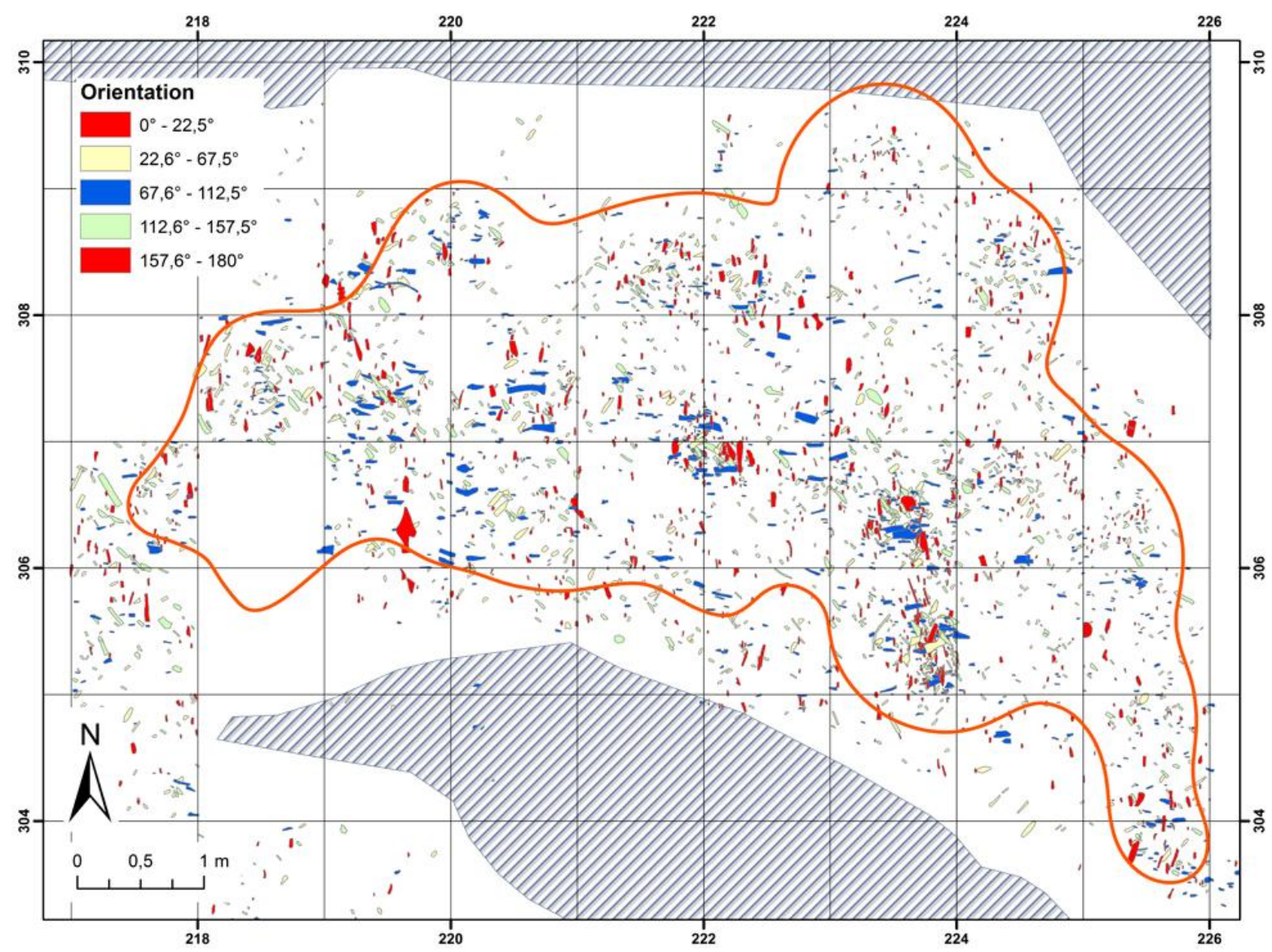

Figure 9. Detailed view of the distribution of finds within the main concentration area at the bottom of find horizon B (sub-horizon B3). The red outline indicates the main accumulation of archaeological finds. Notice that North-South orientations are defined by two different azimuths (0-22.5 and $\left.157.6-180^{\circ}\right)$.

The faunal material across the NN2 site and within the NN2/2B horizon illustrates a relative uniformity in terms of preservation state and taphonomic modification (Kindler et al. 2014). Whilst there is some evidence for heavily weathered material, most bone remains suggest rapid incorporation and burial within the loam deposits at NN2. Detailed taphonomic analyses have not identified any evidence for hydrological modification in terms of the rounding of edges or specimens (Stopp 1997). Similarly, lithics are generally not eroded and in a relatively "fresh" condition, suggesting no or limited transport (Pop 2014). Very limited evidence of carnivore activity has been detected-less than $1 \%$ of the faunal assemblage show damage produced by carnivore. This indicates that carnivores played a minor role in the formation of the deposit (Kindler et al. 2014). Most of the 
refits identified up to date are within short distances, which suggests that bone fragments suffered little transport (Kindler et al. 2014 and Supplementary Material Figure 6).

Finally, size sorting in artefact distribution is also considered an indicator of transport by water flow (Behrensmeyer 1990). Slow water flow can move small fragments more easily than larger ones, and therefore the lack of small fragments in archaeological assemblages could be due to hydrological processes (Petraglia and Potts 1994; Schick 1986), amongst others (preservation, recovery strategies, etc.). Preliminary analyses of the spatial distribution of bone fragments indicate that smaller fragments are well represented in the northern, upslope area (Supplementary Material Figure 7). This pattern is consistent with the distribution of lithics (Pop et al., 2015). Small fragments tend to concentrate in the main accumulation area, where the fragmentation of the faunal material is higher, probably due to intense human activity. The lack of winnowing and the presence of small elements alongside large ones, including heavy manuports, all over the site does exclude differential transport (Kindler et al. 2014; Pop 2014; Pop et al., 2015).

Taken together, these multi-faceted analyses suggest that high-energy processes can be excluded in the accumulation and post-depositional history of the NN2 site (see Domínguez-Rodrigo et al. 2014). However, the presence of preferred orientations in some areas of Neumark-Nord 2/2B, and the identification of different patterns of preferential orientation -uniform, linear and multimodalsuggests that different low-energy processes played some role in the reorientation of the deposit.

Evaluating the nature of these processes is difficult, especially in dynamic contexts such as lake margins. Moreover, the faunal assemblage at NN2/2B is highly fragmented due to human processing, which hinders the comparison with most of experimental observations, especially in the case of specific bone specimens (Domínguez-Rodrigo et al. 2014). Linear orientations usually relates to strong currents (Behrensmeyer 1990; Petraglia and Potts 1994). However, as stated before, there is no evidence for high-energy hydrological processes necessary to produce a significant movement of the assemblage (Walker and Trauth 2013; Domínguez-Rodrigo et al. 2014). Experiments show that low-energy water flow can create linear distributions at in-situ sites, without a significant transport of artefacts (Cobo-Sánchez et al. 2014; Domínguez-Rodrigo et al. 2014). This might be the case at NN2/2B, where artefacts from some particular areas were re-oriented, without any significant, longdistance transport of the archaeological materials. Our hydrological model supports previous evidence (Klinkenberg 2010; Hesse and Kindler 2014; Pop et al., 2015) that some shallow channels could have ran from north to south. These channels or gullies could have been responsible for the re-orientation of the artefacts. Other processes, such as trampling, can also result in linear orientations, usually parallel to the walking direction (Benito-Calvo et al. 2011). However, it seems unlikely that movements within an open environment such as a lake margin were regular enough to create such pattern.

In some areas of the excavated surface, as in the southern part of the main concentration area, finds show bimodal patterns. In many of these units, one of the preferred orientations is perpendicular to the estimated direction of water flow. Perpendicular-to-the-slope orientations can be linked to shallow waters and low energy hydrological processes (Behrensmeyer 1990; Walter and Trauth 2013). Elongated artefacts rolling downslope -due to either gravity or hydrodynamics- can result in perpendicular orientations, as can be wave action in shallow waters, such as lakeshores. interpretation for the preferential orientations observed within the assemblage. The lack of 
evidence for high-energy processes and a significant transport of the material points to low-energy hydrodynamic processes as the main erosional and post-depositional processes influencing the deposit. These processes would have resulted in an in-situ reorientation of part of the archaeological assemblage, while mass transport or a major reworking of the assemblage can be excluded.

The intense processing of the carcasses by hominins (cut and impact marks, burnt bones, long bones showing fresh spiral fractures) (Kindler et al. 2014), the large number of lithics recovered at the site covering different stages of the chaine operatoire (Pop 2014), and the very limited access for carnivores to the carcasses (Kindler et al. 2014) suggest that Neanderthals were the main (if not the only) agent of accumulation in Neumark-Nord 2. Our results indicate that high-energy hydrodynamic processes did not play a role in the formation of the deposit, and therefore the original distribution was not modified substantially. The limited influence of hydrological processes on the NN2/2B archaeological deposit permits more extensive analyses regarding Neanderthal spatial behaviour. In this sense, the site of Neumark-Nord 2 provides a solid basis for the consistent analysis of Neanderthal behaviour and adaptations to temperate, lacustrine environments.

\section{ACKNOWLEDGEMENTS}

The project "Interglacial landscapes and Neanderthal adaptations in the Neumark-Nord region (Saxony-Anhalt)" is funded by the Deutsche Forchungsgemeinschaft (DFG).

\section{REFERENCES}

Bakels, C. C., 2014. A reconstruction of the vegetation in and around the Neumark-Nord 2 basin, based on a pollen diagram from the key section HP7 supplemented by HP10, in: GaudzinskiWindheuser, S., Roebroeks, W. (Eds.), Multidisciplinary studies of the Middle Palaeolithic record from Neumark-Nord (Germany). Landesamt für Denkmalplege und Archäologie Sachsen-Anhalt Landesmuseum für Vorgeschichte Halle, Saale, pp. 97-107.

Bakels, C. C., 2012. Non-pollen palynomorphs from the Eemian pool Neumark-Nord 2: determining water quality and the source of high pollen-percentages of herbaceous taxa. Review of Palaeobotany and Palynology 186, 58-61. DOI:10.1016/j.revpalbo.2012.06.003

Behrensmeyer, A. K., 1990. Transport/Hydrodynamics of bones, in: Briggs, D. E. G., Crowther, P. R. (Eds.), Palaeobiology: a synthesis. Blackwell Scientific Publications, Oxford, pp. 232-235.

Behrensmeyer, A. K., 1982. Time and resolution in fluvial vertebrae assemblages. Paleobiology 8 (3), 211-227. http://www.jstor.org/stable/2400407

Benito-Calvo, A., de la Torre, I., 2011. Analysis of orientation patterns in Olduvai Bed I assemblages using GIS techniques: implications for site formation processes. Journal of Human Evolution 61 (1), 50-60. DOI:10.1016/j.jhevol.2011.02.011

Benito-Calvo, A., Martínez-Moreno, J., Mora, R., Roy, M., Roda, X., 2011. Trampling experiments at Cova Gran de Santa Linya, Pre-Pyrenees, Spain: their relevance for archaeological fabrics of the Upper-Middle Paleolithic assemblages. Journal of Archaeological Science 38: 3652-3661.

DOI:10.1016/j.jas.2011.08.036 
Bertran, P., Lenoble, A., 2002. Fabriques des niveaux archéologiques: méthode et premier bilan des apports à l'étude taphonomique des sites paléolithiques. Paleo 14, http://paleo.revues.org/1383.

Bertran, P., Texier, J.-P., 1999. Sedimentation processes and facies on a semi-vegetated talus, Lousteau, Southwestern France. Earth Surface processes and Landforms 24: 177-187. DOI: $10.1002 /(\mathrm{SICl}) 1096-9837(199902) 24: 2$

Boschian, G., Saccà, D., 2010. Ambiguities in human and elephant interactions? Stories of bones, sand and water from Castel di Guido (Italy). Quaternary International 214, 3-16. DOI:10.1016/j.quaint.2009.10.016

Britton, K., Gaudzinski-Windheuser, S., Roebroeks, W., Kindler, L., Richards, M. P., 2014. Stable isotope evidence for herbivore palaeoecology at Neumark-Nord 2, in: Gaudzinski-Windheuser, S., Roebroeks, W. (Eds.), Multidisciplinary studies of the Middle Palaeolithic record from Neumark-Nord (Germany). Landesamt für Denkmalplege und Archäologie Sachsen-Anhalt - Landesmuseum für Vorgeschichte Halle, Saale, pp. 211-219.

Britton, K., Gaudzinski-Windheuser, S., Roebroeks, W., Kindler, L., Richards, M. P., 2012. Stable isotope analysis of well-preserved 120.000 year-old herbivore bone collagen from the Middle Palaeolithic site of Neumark-Nord 2, Germany reveals niche separation between bovids and equids. Palaeogeography, Palaeoclimatology, Palaeoecology 333-334: 168-177. DOI:10.1016/j.palaeo.2012.03.028

Cobo-Sánchez, L., Aramendi, J., Domínguez-Rodrigo, M., 2014. Orientation patterns of wildebeest bones on the lake Masek floodplain (Serengeti, Tanzania) and their relevance to interpret anisotropy in the Olduvai lacustrine floodplain. Quaternary International 322-323: 277-284.

DOI:10.1016/j.quaint.2013.07.130

Cunnane, S. C., Stewart, K. M. (Eds.), 2010. Human brain evolution. The influence of freshwater and marine food resources. John Wiley \& Sons, Inc., Hoboken.

Davis, J. C., 2002. Statistics and data analysis in Geology. Third Edition. J. Wiley, New York.

De la Torre, I., Benito-Calvo, A., 2013. Application of GIS methods to retrieve orientation patterns from imagery; a case study from Beds I and II, Olduvai Gorge (Tanzania). Journal of Archaeological Science 40 (5): 2446-2457. DOI:10.1016/j.jas.2013.01.004

Dinnin, M., Van de Noort, R., 1999. Wetland hábitats, their resource potential and exploitation, in: Coles, B., Coles, J., Jorgensen, M.S. (Eds.), Bog bodies, sacred sites and Wetland Archaeology. Proceedings of a conference held by WARP and the National Museum of Denmark, in conjunction with Silkeborg Museum, Jutland, September1996. WARP (Wetland Archaeology Research Project), Exeter, pp. 69-78.

Domínguez-Rodrigo, M., Uribelarrea, D., Santonja, M., Bunn, H. T., García-Pérez, A., Pérez-González, A., Panera, J., Rubio-Jara, S., Mabulla, A., Baquedano, E., Yravedra, J., Díez-Martín, F., 2014. Autochthonous anisotropy of archaeological materials by the action of water: experimental and archaeological reassessment of the orientation patterns at the Olduvai sites. Journal of Archaeological Science 41: 44-68. DOI:10.1016/j.jas.2013.07.025

Domínguez-Rodrigo, M., García-Pérez, A., 2013. Testing the accuracy of different A-axis types for measuring the orientation of bones in the archaeological record. PlosOne 8 (7): e68955. DOI:10.1371/journal.pone.0068955 
Gamble, C. E., 1987. Man the shoveler: alternative models for Middle Pleistocene colonization and occupation in northern latitudes, in: Soffer, O. (Ed.), The Pleistocene Old World: regional perspectives. Plenum Press, New York, pp. 81-98.

4 Gamble, C. E., 1986. The Palaeolithic settlement of Europe. Cambridge University Press, Cambridge.

5 Gaudzinski-Windheuser, S., Roebroeks, W. (Eds.), 2014. Multidisciplinary studies of the Middle

6 Palaeolithic record from Neumark-Nord (Germany). Landesamt für Denkmalplege und Archäologie

7 Sachsen-Anhalt - Landesmuseum für Vorgeschichte Halle, Saale.

8 Gaudzinski-Windheuser, S., Kindler, L., Pop, E., Roebroeks, W., Smith, G., 2014. The Eemian

9 Interglacial lake-landscape at Neumark-Nord (Germany) and its potential for our knowledge of

10 hominin subsistence strategies. Quaternary International 331: 31-38.

11 DOI:10.1016/j.quaint.2013.07.023

12 Gaudzinski-Windheuser, S., Kindler, L., 2012. Research perspectives for the study of Neandertal subsistence strategies based on the analysis of archaeozoological assemblages. Quaternary International 247: 59-68. DOI:10.1016/j.quaint.2010.11.029

Gaudzinski-Windheuser, S., Roebroeks, W., 2011. On Neanderthal Subsistence in Last Interglacial forested environments in Northern Europe, in: Conard, N., Richter, J. (Eds.), Neanderthal Lifeways, Subsistence and Technology. Vertebrate Paleobiology and Paleoanthropology 19. Springer Netherlands, pp. 61-71.

Hageman, J.B., Bennett, D.A., 2000. Construction of Digital Elevation Models for archaeological applications, in: Wescott, K., Brandon, R.J. (Eds.), Practical applications of GIS for archaeologists: a predictive modelling toolkit. Taylor and Francis, London, pp. 121-136.

Hanson, C. B., 1980. Fluvial taphonomic processes: models and experiments, in: Behrensmeyer, A. K., Hill, A. (Eds.), Fossils in the making. University of Chicago Press, Chicago, pp. 156-181.

Heinrich, W.-D., 2014. Remains of small mammals from Pleistocene basin deposits of Neumark-Nord 2, central Germany, in: Gaudzinski-Windheuser, S., Roebroeks, W. (Eds.), Multidisciplinary studies of the Middle Palaeolithic record from Neumark-Nord (Germany). Landesamt für Denkmalplege und Archäologie Sachsen-Anhalt - Landesmuseum für Vorgeschichte Halle, Saale, pp. 137-142.

Hesse, N., Kindler, L., 2014. Geologie und Genese der quartären Beckenfüllung Neumark-Nord 2 und deren Ausgrabung, in: Gaudzinski-Windheuser, S., Roebroeks, W. (Eds.), Multidisciplinary studies of the Middle Palaeolithic record from Neumark-Nord (Germany). Landesamt für Denkmalplege und Archäologie Sachsen-Anhalt - Landesmuseum für Vorgeschichte Halle, Saale, pp. 13-38.

Jurkenas, D., Laurat, T., Brühl, E., 2006. Three archaeological find horizons from the time of the Neanderthals. Preliminary report of the excavations in the lake basin Neumark-Nord 2 (SaxonyAnhalt, Germany). Archaeologia Baltica 7: 209-232.

Kindler, L., Smith, G., Wagner, M., 2014. Introduction to faunal analysis at Neumark-Nord 2, in: Gaudzinski-Windheuser, S., Roebroeks, W. (Eds.), Multidisciplinary studies of the Middle Palaeolithic record from Neumark-Nord (Germany). Landesamt für Denkmalplege und Archäologie SachsenAnhalt - Landesmuseum für Vorgeschichte Halle, Saale, pp. 197-209.

Klinkenberg, M.V., 2010. On a distorted distribution Spatial Analysis of find material from the Eemian open air site Neumark Nord 2/2. Master Thesis Palaeolithic Archaeology. University of Leiden, Faculty of Archaeology, Leiden. 
Kuijper, W. J., 2014. Investigation of inorganic, botanical and zoological remains of an exposure of Last Interglacial (Eemian) sediments at Neumark-Nord 2 (Germany), in: Gaudzinski-Windheuser, S., Roebroeks, W. (Eds.), Multidisciplinary studies of the Middle Palaeolithic record from Neumark-Nord (Germany). Landesamt für Denkmalplege und Archäologie Sachsen-Anhalt - Landesmuseum für Vorgeschichte Halle, Saale, pp. 79-95.

Lenoble, A., Bertran, P., 2004. Fabric of Palaeolithic levels: methods and implications for site formation processes. Journal of Archaeological Science 31: 457-469. DOI:10.1016/j.jas.2003.09.013

Mania, D., Meller, H., 2010. Neumark-Nord: ein interglaziales Ökosystem des mittelpaläolithischen

9 Menschen. Landesmuseum für Vorgeschichte, Landesamt für Denkmalpflege und Archäologie Sachsen-Anhalt, Saale.

McPherron, S. J. P., 2005. Artifact orientations and site formation processes from total station proveniences. Journal of Archaeological Science 32: 1003-1014. DOI:10.1016/j.jas.2005.01.015

Mücher, H. J., 2014. Neumark-Nord 2, a shallow Eemian pool in northern central Germany - a micromorphical study of its infill, in: Gaudzinski-Windheuser, S., Roebroeks, W. (Eds.), Multidisciplinary studies of the Middle Palaeolithic record from Neumark-Nord (Germany). Landesamt für Denkmalplege und Archäologie Sachsen-Anhalt - Landesmuseum für Vorgeschichte Halle, Saale, pp. 39-46.

Nicholas, G. P., 2006. Prehistoric Hunter-Gatherers in Wetland Environments: theoretical issues, economic organization and resource management strategies. In Lillie, M., Ellis, S. (Eds.), Wetlands: local issues, World perspectives. Oxbow Press, Oxford, pp. 46-62.

Nicholas, G. P., 1998. Wetlands and hunter-gatherers: a global perspective. Current Anthropology 39

Petraglia, M. D., Potts, R., 1994. Water flow and the formation of Early Pleistocene artefact sites in Olduvai Gorge, Tanzania. Journal of Anthropological Archaeology 13: 228-254. DOI:10.1006/jaar.1994.1014

Petraglia, M., Nash, D. T., 1987. The impact of fluvial processes on experimental sites, in: Nash, D. T., Petraglia, M. (Eds.), Natural formation processes and the archaeological record. BAR International Series 352, Oxford, pp. 108-130.

Pop, E., 2014. Analysis of the Neumark-Nord 2/2 lithic assemblage: results and interpretations, in: Gaudzinski-Windheuser, S., Roebroeks, W. (Eds.), Multidisciplinary studies of the Middle Palaeolithic record from Neumark-Nord (Germany). Landesamt für Denkmalplege und Archäologie SachsenAnhalt - Landesmuseum für Vorgeschichte Halle, Saale, pp. 143-195.

Pop, E., Bakels, C., Kuijper, W., Mücher, H., van Dijk, M., 2015. The dynamics of small postglacial lake basins and the nature of their archaeological record: a case study of the Middle Palaeolithic site Neumark-Nord 2, Germany. Geoarchaeology 30: 393-413. DOI:10.1002/gea.21526

Richter, D., Krbetschek, M., 2014. Preliminary luminescence dating results for two Middle Palaeolithic occupations at Neumark-Nord 2, in: Gaudzinski-Windheuser, S., Roebroeks, W. (Eds.), Multidisciplinary studies of the Middle Palaeolithic record from Neumark-Nord (Germany). Landesamt für Denkmalplege und Archäologie Sachsen-Anhalt - Landesmuseum für Vorgeschichte Halle, Saale, pp. 131-136. 
Roebroeks, W., Conard, N. J., van Kolfschoten, T., 1992. Dense forest, cold steppes, and the Palaeolithic settlement of Northern Europe. Current Anthropology 33 (5): 551-586.

3 http://www.jstor.org/stable/2743916

Schick, K. D., 1986. Stone Age sites in the making. Experiments in the formation and transportation of archaeological occurrences. BAR International Series 319, British Archaeological Reports, Oxford.

Schiffer, M. B., 1987. Formation processes of the archaeological record. University of New Mexico

Schiffer, M. B., 1983. Toward the identification of formation processes. American Antiquity 48 (4): 675-706. http://www.jstor.org/stable/279771

Sier, M. K., Deckers, M. J., 2014. Magnetic property analyisis as palaeoenvironmental proxy: a case study of the Last Interglacial Middle Palaeolithic site at Neumark-Nord 2 (Germany), in: GaudzinskiWindheuser, S., Roebroeks, W. (Eds.), Multidisciplinary studies of the Middle Palaeolithic record from Neumark-Nord (Germany). Landesamt für Denkmalplege und Archäologie Sachsen-Anhalt Landesmuseum für Vorgeschichte Halle, Saale, pp. 117-130. Windheuser, S., Hesse, N., Jagich, A., Kindler, L., Kuijper, W. J., Laurat, T., Mücher, H. J., Penkman, K. E. H., Richter, D., van Hinsbergen, D. J., 2011. Direct terrestrial-marine correlation demonstrates surprisingly late onset of the last interglacial in central Europe. Quaternary Research 75 (1): 213-218. DOI:10.1016/j.yqres.2010.11.003

Stein, J. K., 2001. A review of site formation processes and their relevance to Geoarchaeology, in: Goldberg, P., Holliday, V. T., Ferring, C. R. (Eds.), Earth Sciences and Archaeology. Kluwer Academic / Plenum Publishers, New York.

Stopp, M., 1997. Early Human Adaptation in the Northern Hemisphere and the Implications of Taphonomy. British Archaeological Reports, Oxford.

Strahl, J., Krbetschek, M. R., Luckert, J., Machalett, B., Meng, S., Oches, E. A., Rappsilber, I., Wansa, S., Zöller, L., 2010. Geologie, Paläontologie und Geochronologie des Eem-Beckens Neumark-Nord 2 und Vergleich mit dem Becken Neumark-Nord 1 (Geiseltal, Sachsen-Anhalt). Quaternary Science Journal 59: 120-167. DOI:10.3285/eg.59.1-2.09

Van de Noort, R., 2008. The Archaeology of Wetland Landscapes: method and theory at the beginning of the $21^{\text {st }}$ Century, in: David, B., Thomas, J. (Eds.), Handbook of Landscape Archaeology. Left Coast Press, Wallnut Creek, pp. 482-489.

Walker, M. J., Trauth, M. H., 2013. A MATLAB based orientation analysis of Acheulean handaxe accumulations in Olorgesailie and Kariandusi, Kenya Rift. Journal of Human Evolution 64: 569-581. DOI: 10.1016/j.jhevol.2013.02.011 


\section{Supplementary material}

2

$\begin{array}{cccc}\begin{array}{c}\text { Depth } \\ (\mathrm{cm})\end{array} & \begin{array}{c}\text { Lithology } \\ \text { Sier et al. 2011 }\end{array} & \begin{array}{c}\text { PAZ } \\ \text { Sier et al. 2011 } \\ \text { Bakels 2014 }\end{array} & \begin{array}{c}\text { Archaeology } \\ \text { Correlation of find levels } \\ \text { with HP7 }\end{array} \\ & \text { Unit Lithology } & & \end{array}$

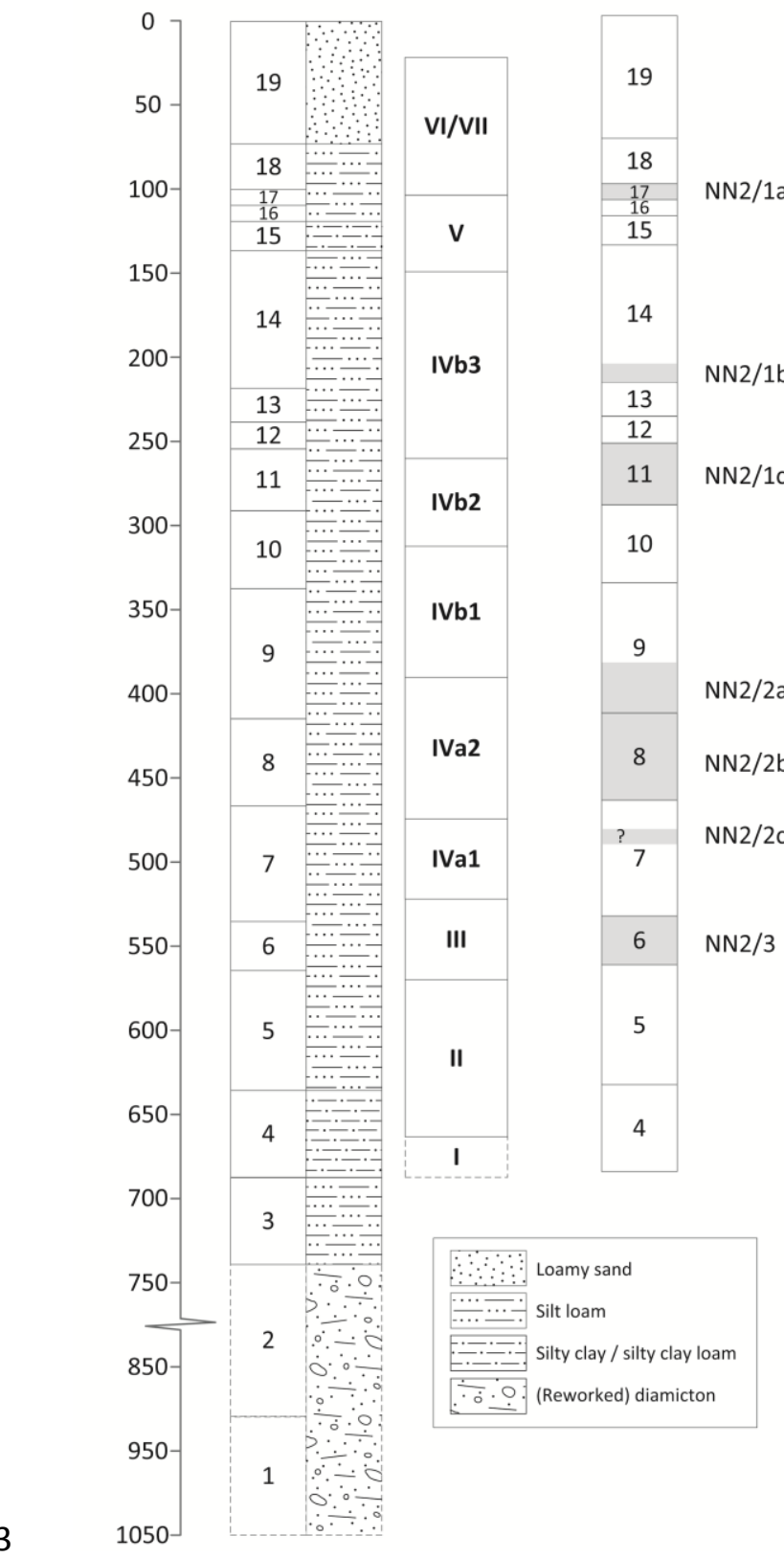

4 Figure 1: Stratigraphical sequence of Neumark-Nord 2, with indication of pollen zones (PAZ) and 5 archaeological find horizons.

6

7

8

9 


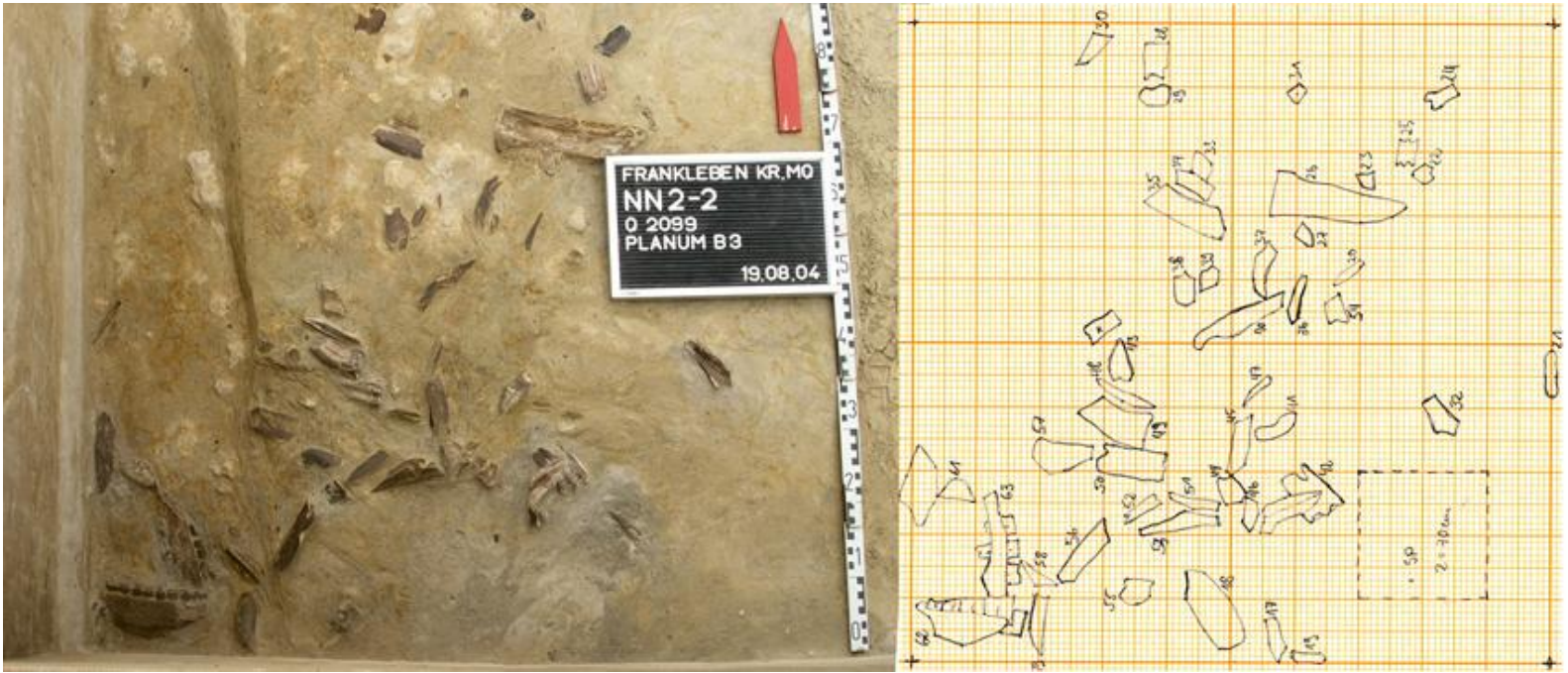

2 Figure 2: Picture of the excavation surface (left) and the corresponding hand drawing (right) of

3 Neumark-Nord 2, level B3, square 2099. The comparison between both images allows estimating the 4 accuracy of the drawings. In terms of orientation, the finds drawn by hand follow the same

5 orientation as seen in the picture. Hand drawings were the base for the digitised drawings used to 6 calculate the orientation of finds. 


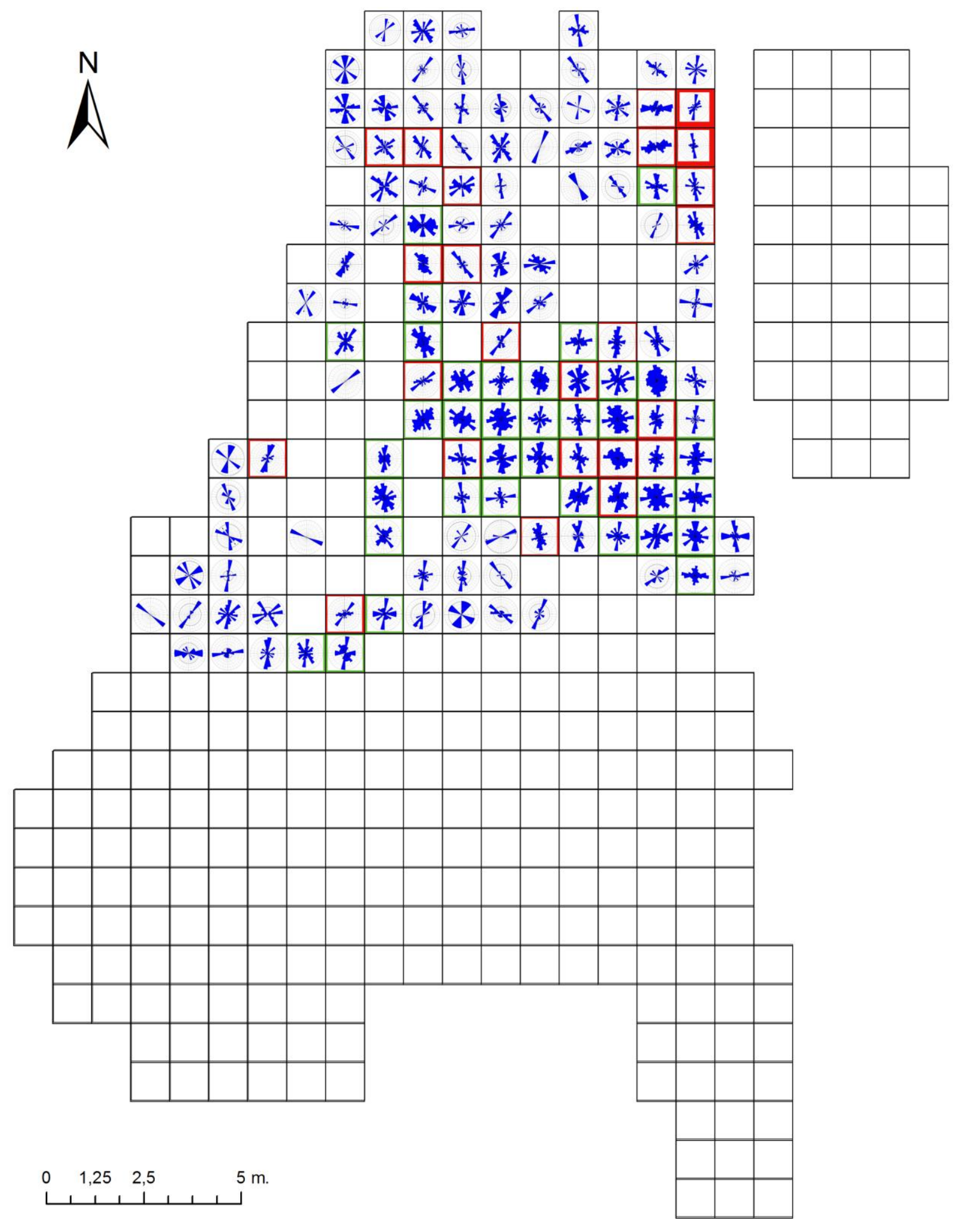

Figure 3: Orientation analysis for Neumark-Nord 2/2B. Rose diagrams indicate the main direction of artefacts. Red outline indicate squares where artefacts show a significant lineal orientation according to a Rayleigh's test, while green outline indicate random orientations. Squares without outline yielded less than 40 elements drawn, and where not considered in the statistical analyses. 


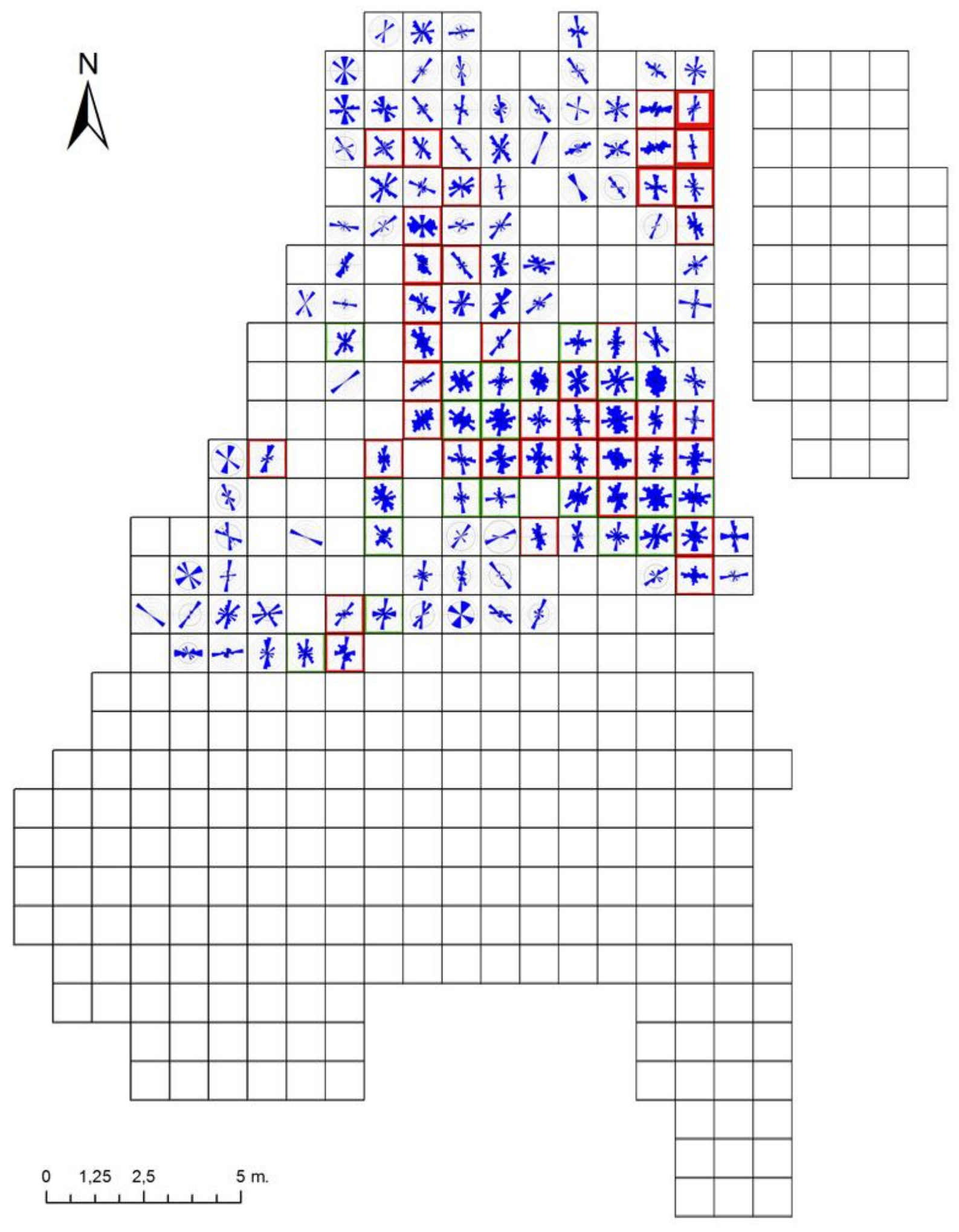

Figure 4: Orientation analysis for Neumark-Nord 2/2B. Rose diagrams indicate the main direction of artefacts. Red outline indicate squares where artefacts show a significant non-uniform orientation according to a Kuiper's test, while green outline indicate random orientations. Squares without outline yielded less than 40 elements drawn, and where not considered in the statistical analyses. 


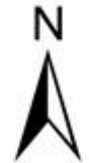

Non-uniform orient.

No
Yes

WDA Disturbance
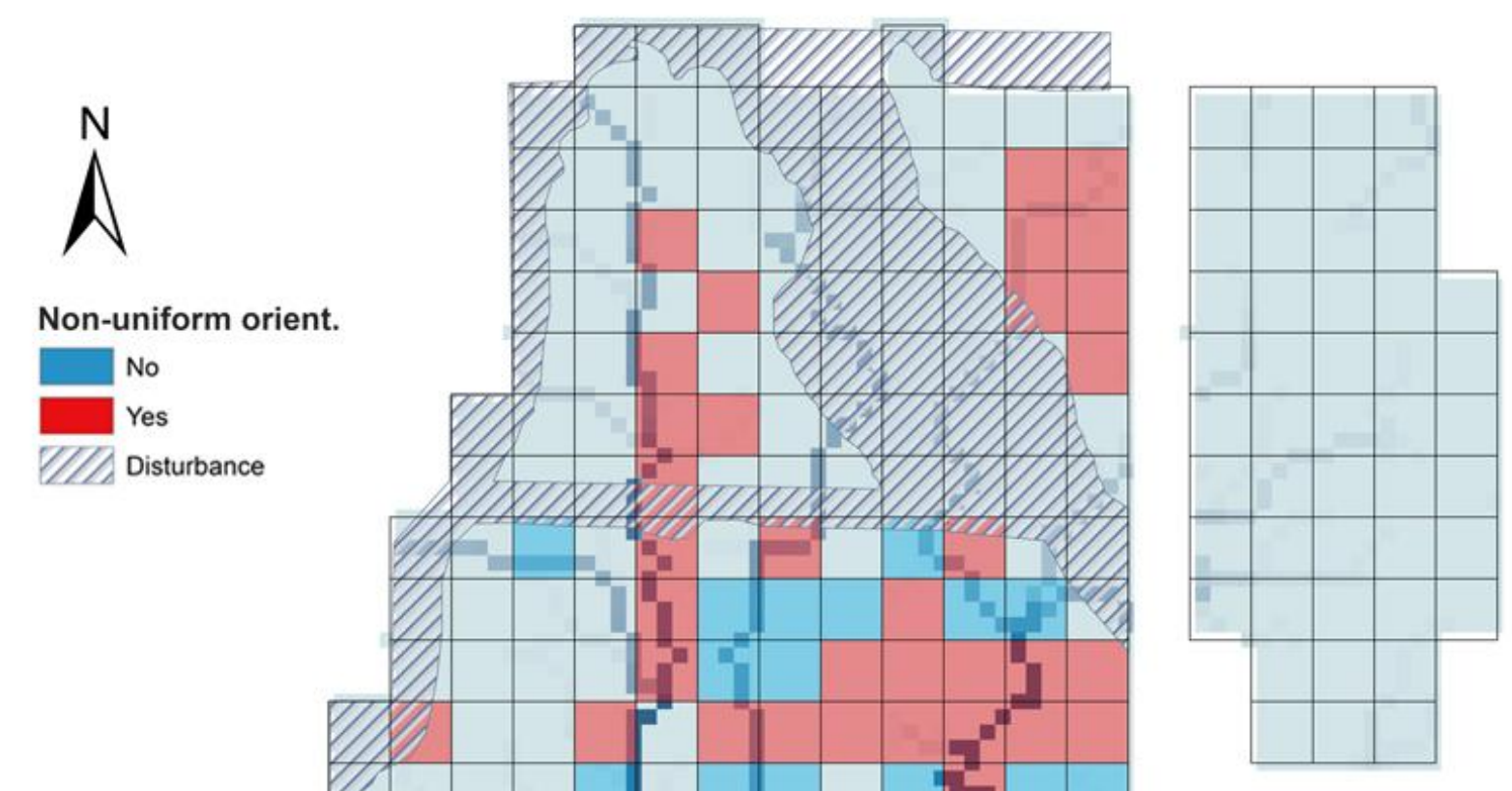

$\begin{array}{llll}0 & 1,25 & 2,5 & 5\end{array}$ Meters

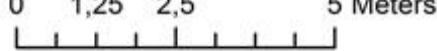

3

4 Figure 5: Hydrological model showing shallow "channels" at the base of NN2 find horizon 2B,

5 compared to orientation of faunal material. Red squares indicate units where bones follow a non-

6 uniform orientation, according to a Kuiper's test. 


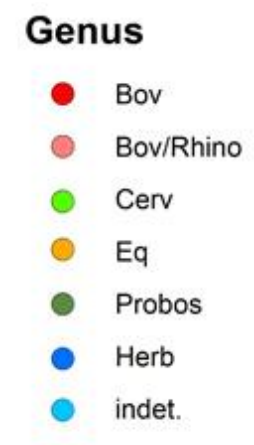

Anat. region

$\begin{array}{ll}\text { A Auto } \\ \text { Axial } \\ \text { Cran } \\ \star & \text { Flat } \\ \star & \text { Lng } \\ \times & \text { indet. }\end{array}$

\section{a}
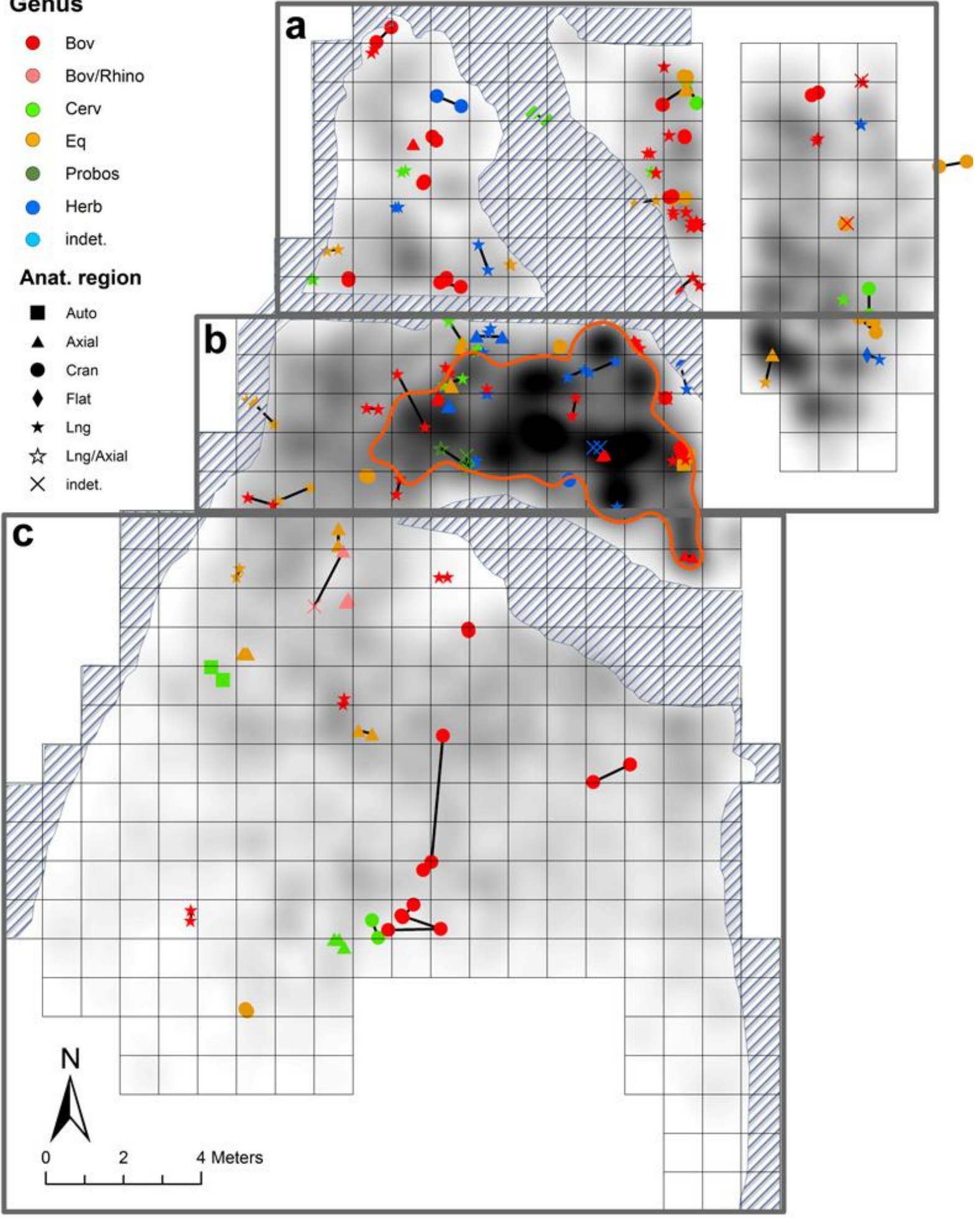

2 Figure 6: Spatial analysis showing the refitting and conjoining bones at Neumark-Nord 2/2B. Most of 3 the refits are shorter than $25 \mathrm{~cm}$, suggesting that the finds suffered little transport. Longer refits appear in the southern part of the site, towards the centre of the basin, were hydrodynamic processes were probably more active. 


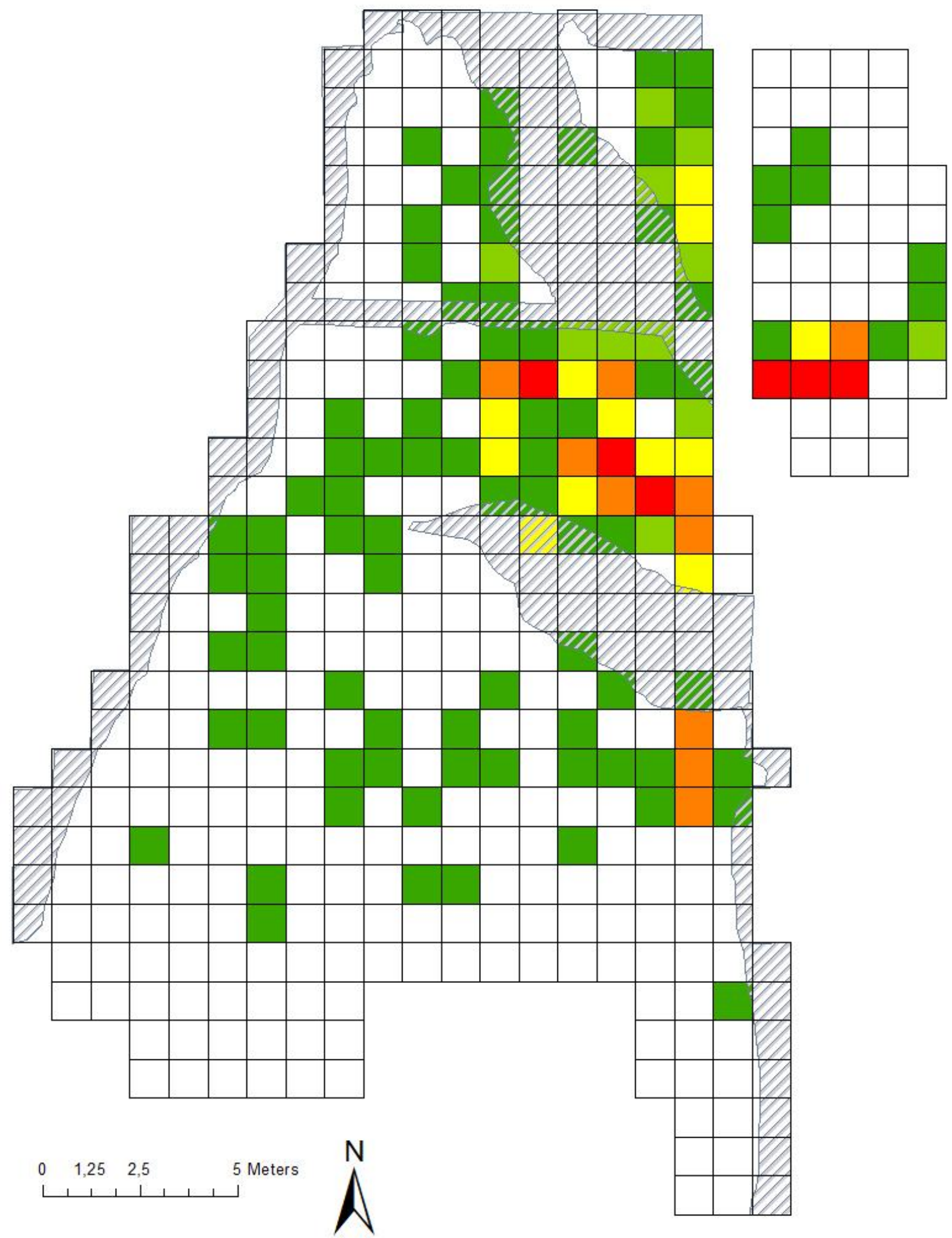

Figure 7: Preliminary analysis of the spatial distribution (frequency by square metre) of faunal remains smaller than $2 \mathrm{~cm}$ long. Red and orange squares indicate squares within the excavation grid where frequency of small fragments is larger. 
2 Table 1: Results of the circular statistical test. Square ID indicates the $1 \times 1 \mathrm{~m}$ units within the 3 excavation grid. Squares shaded in grey contained less than 40 elements and were not considered in 4 the analysis. Rayleigh's test $p$-value in red indicate squares where finds show a preferential 5 orientation. 
Click here to download high resolution image

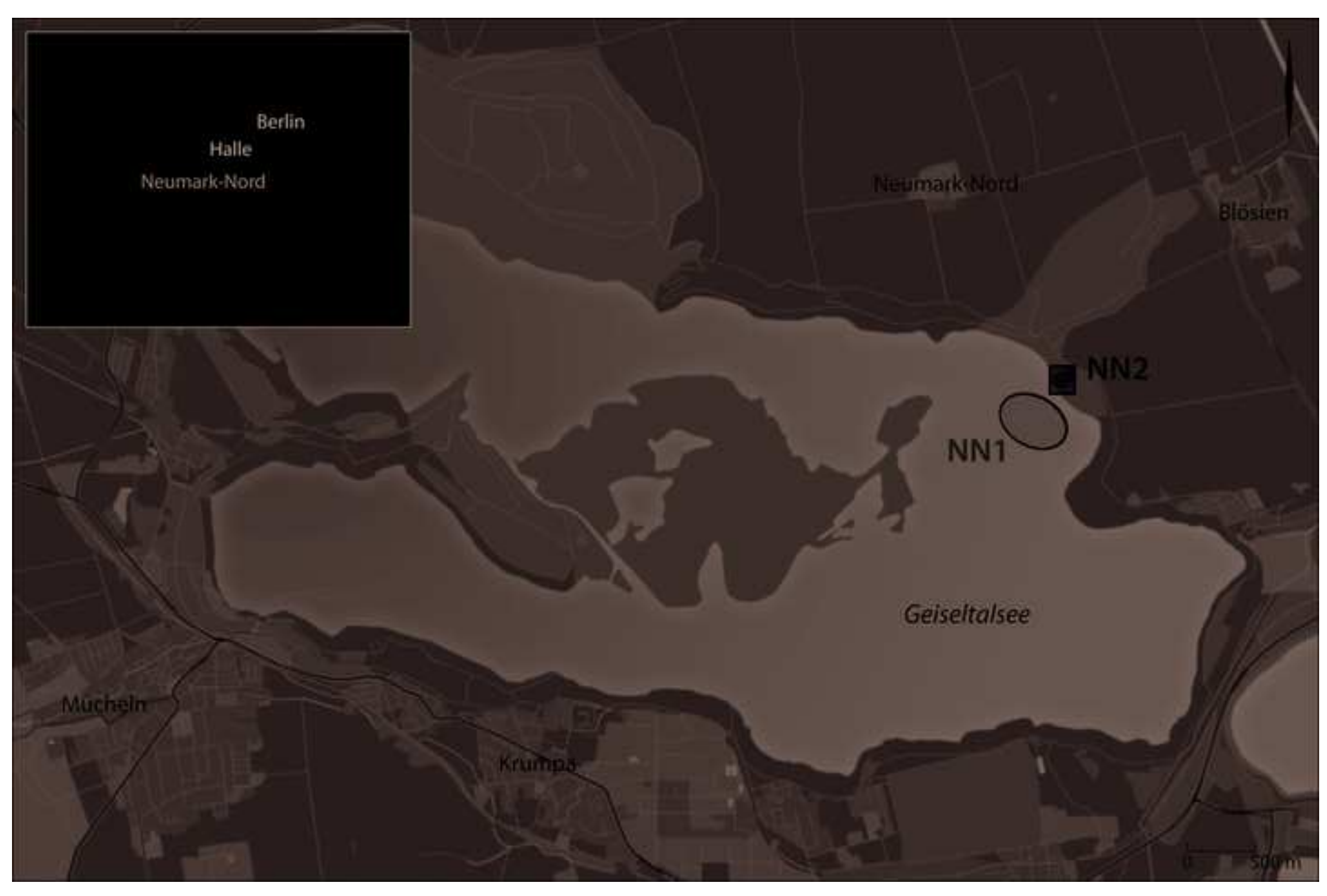


Click here to download high resolution image

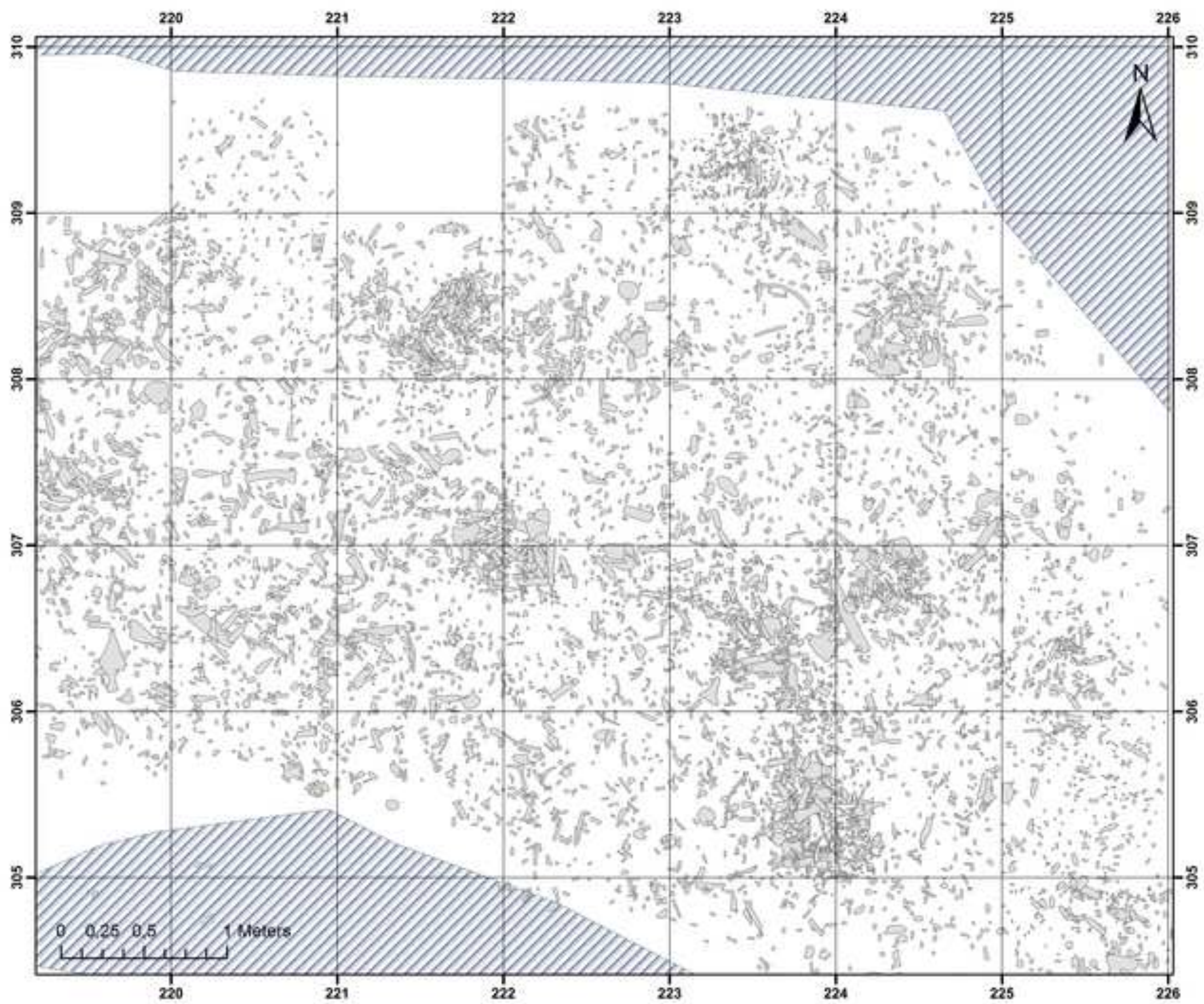


Figure 3
Click here to download high resolution image

\section{NEUMARK-NORD 2/2B}

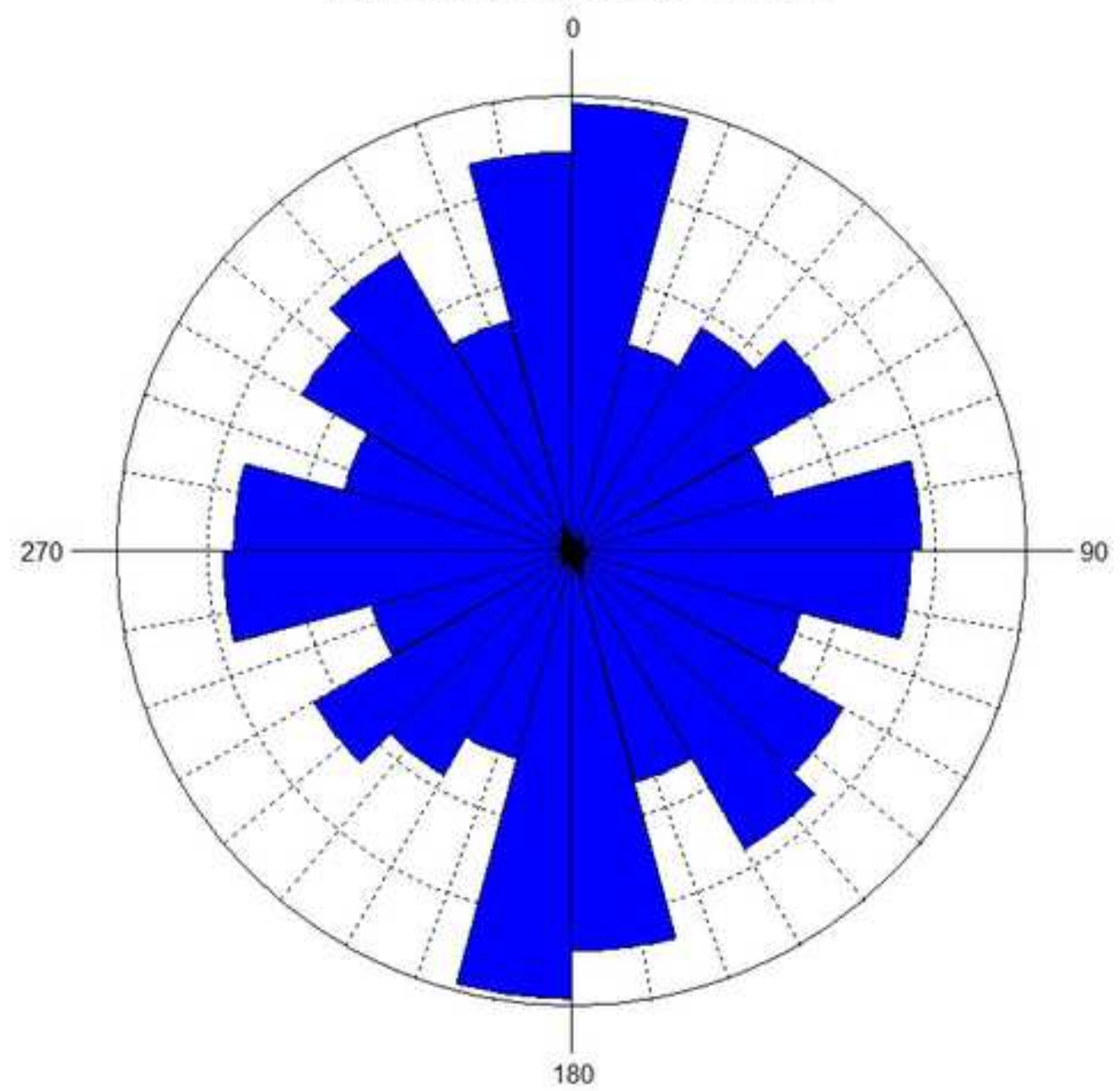


Click here to download high resolution image

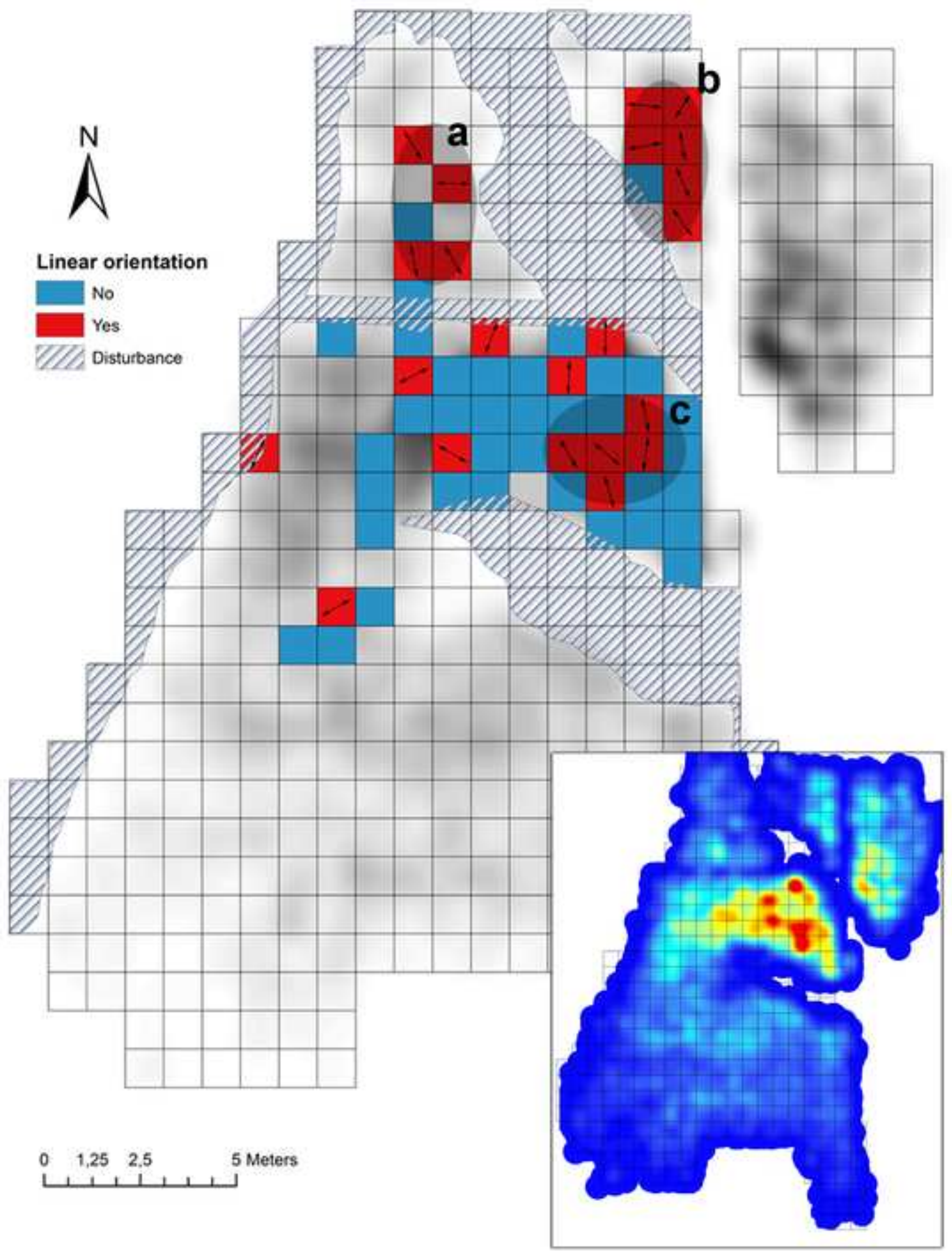




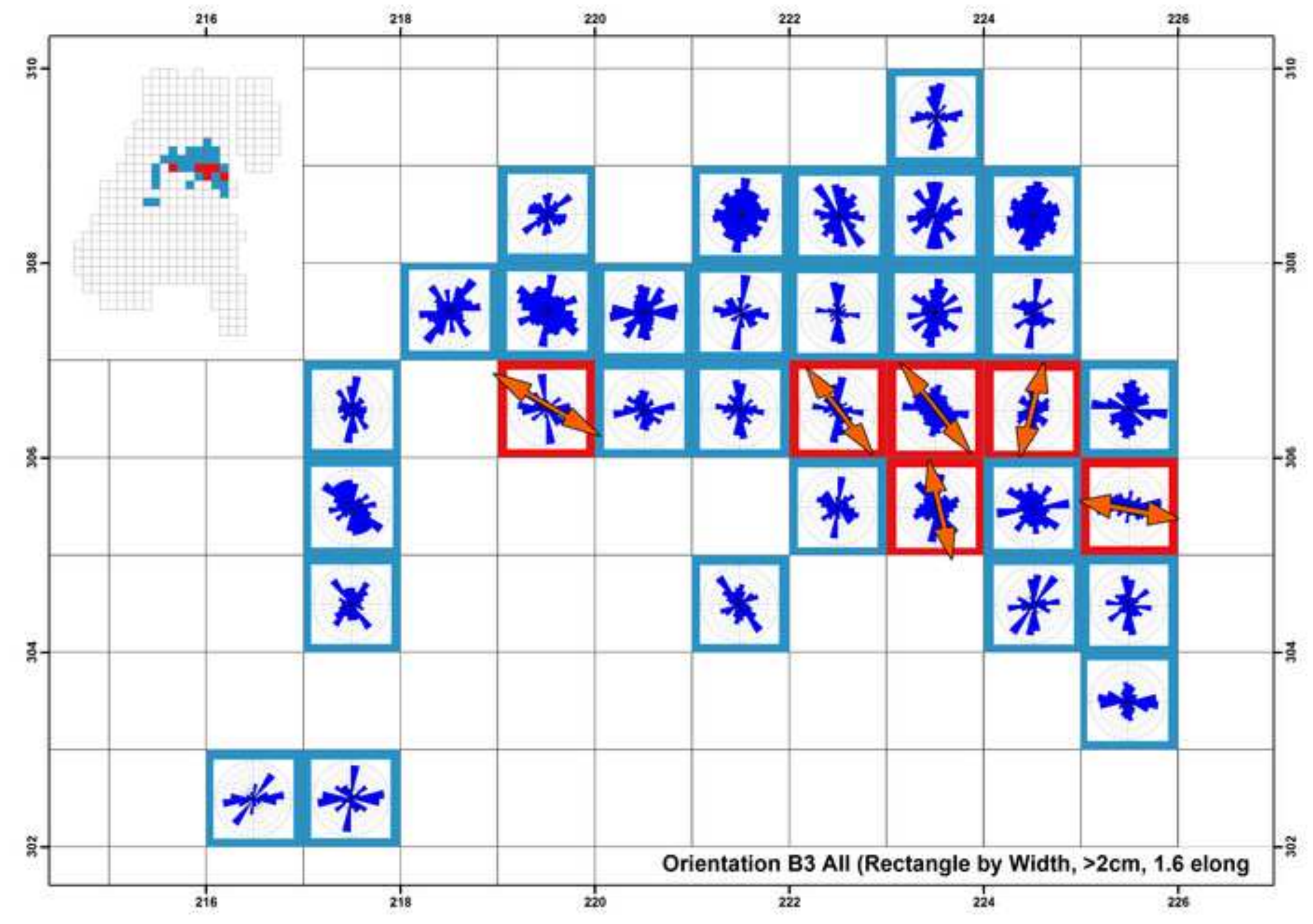


Click here to download high resolution image

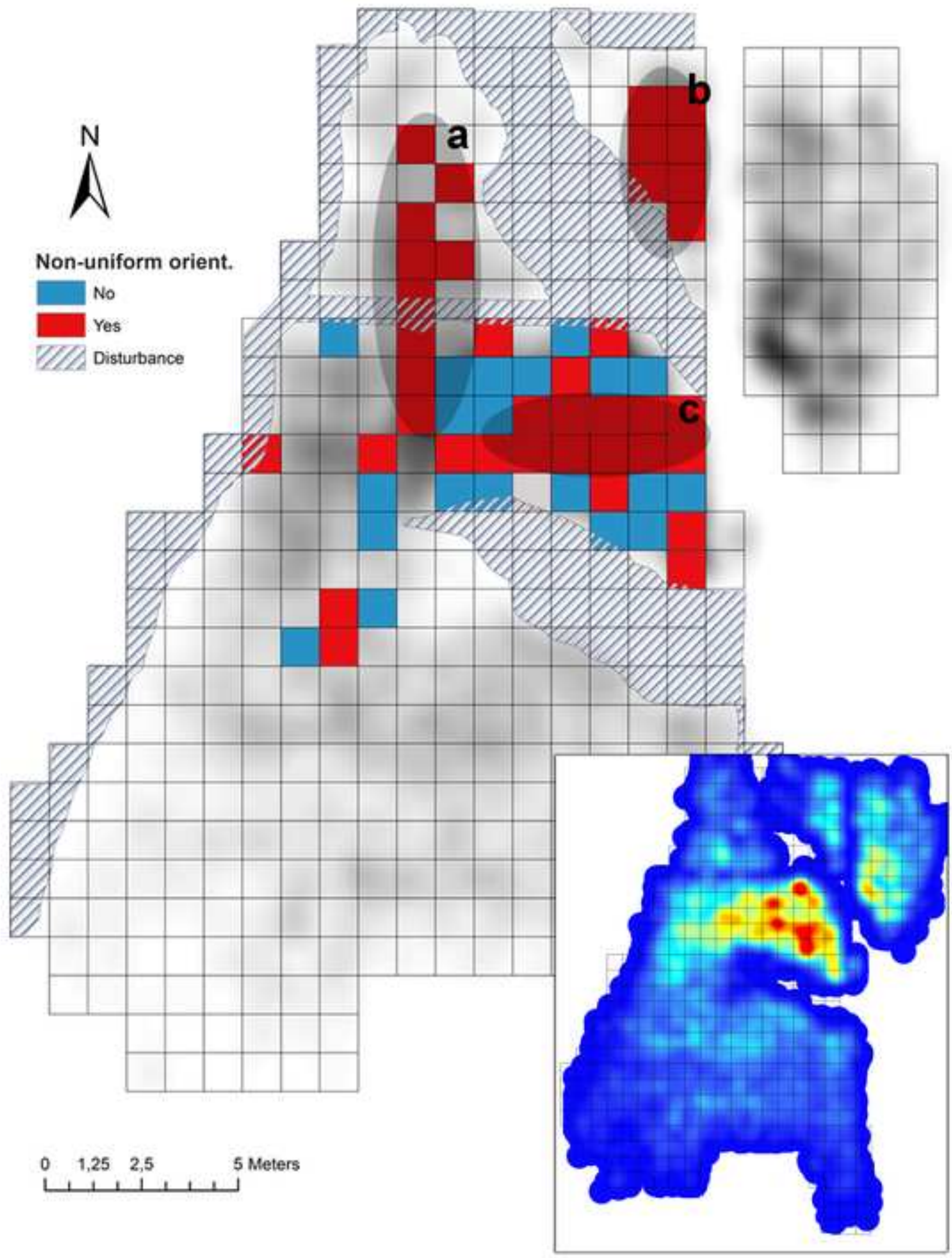




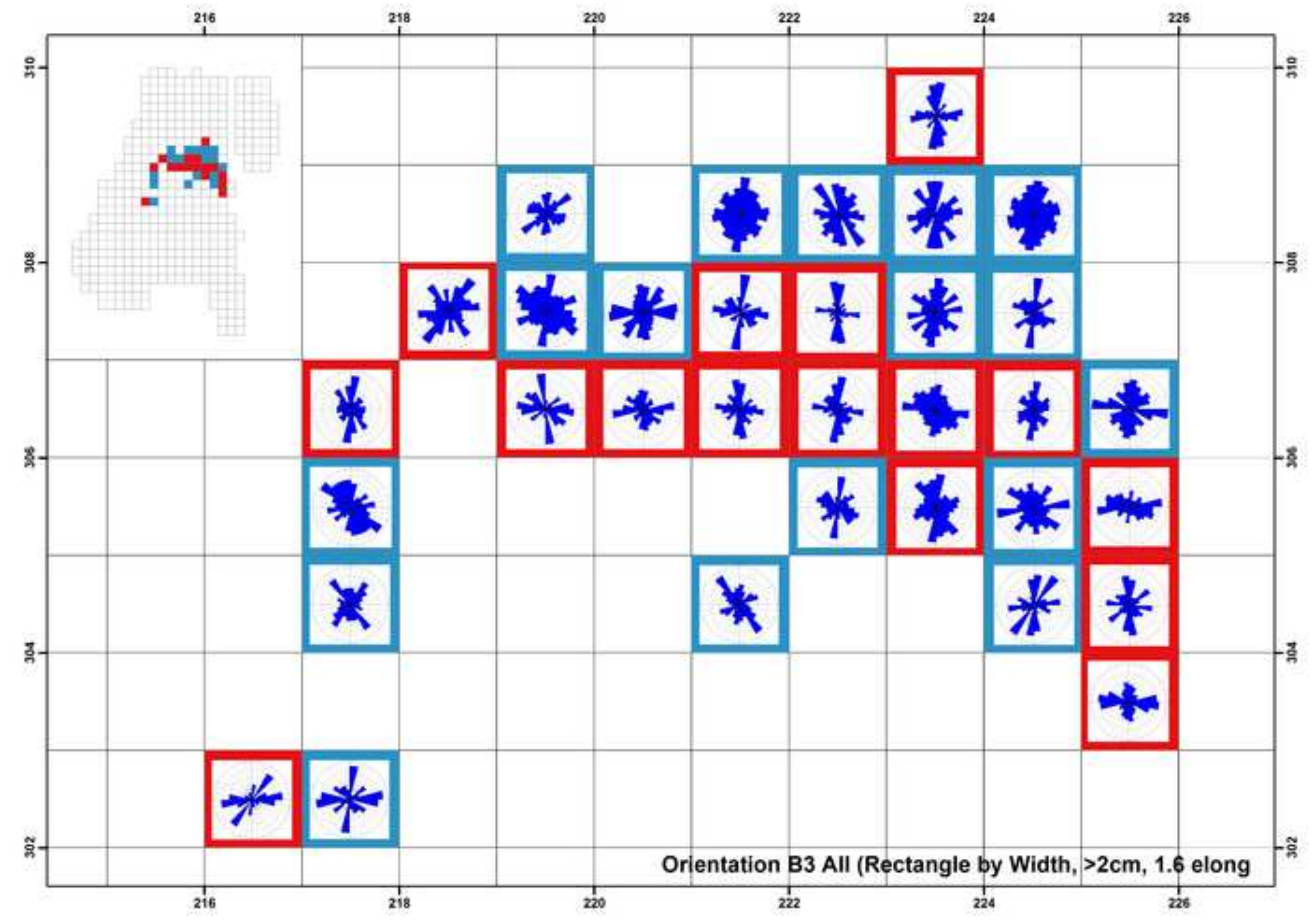

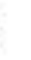

.

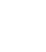


Click here to download high resolution image

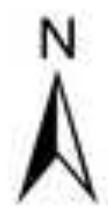

Linear orientation

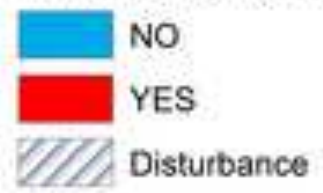

QI/ Disturbance

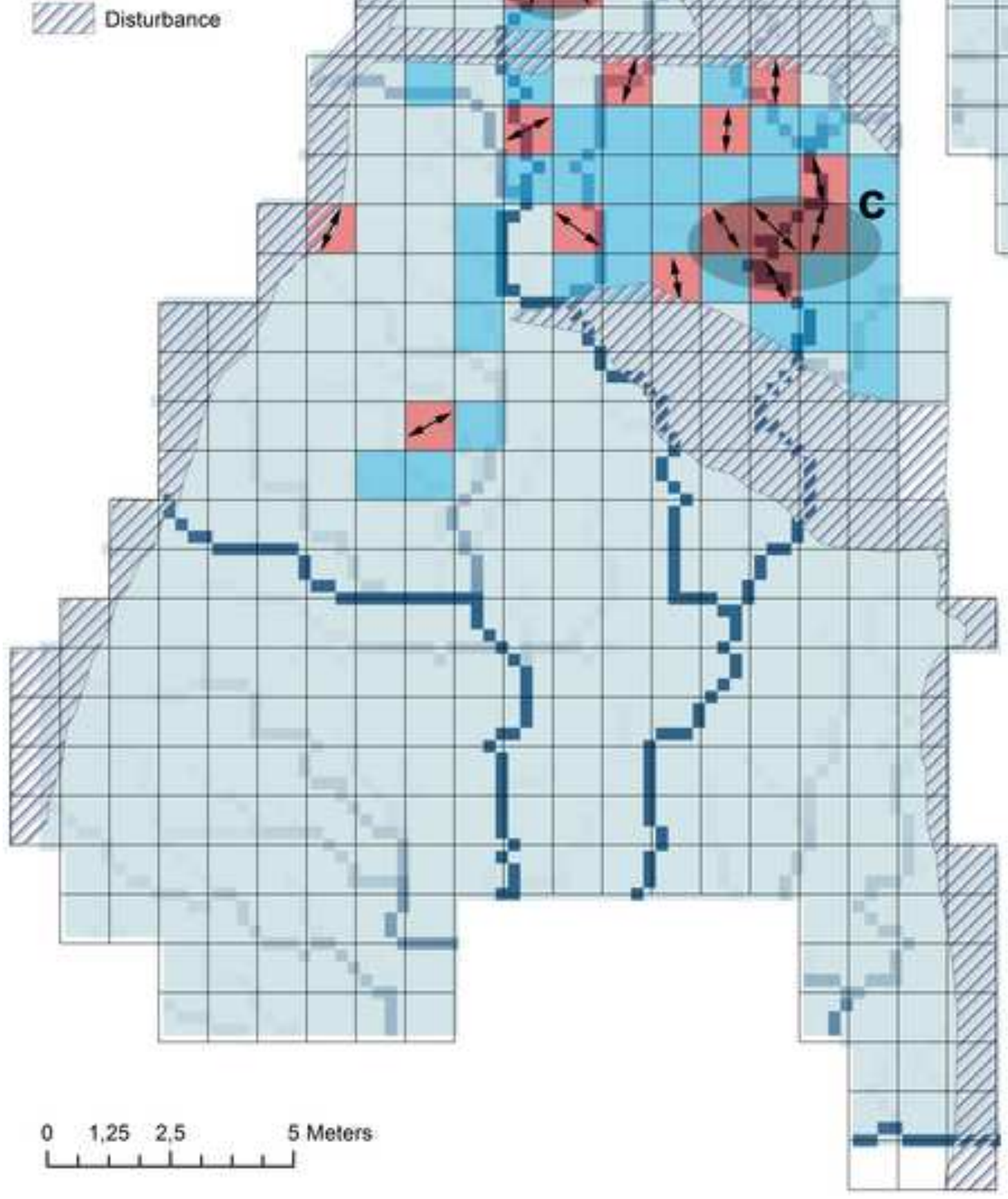


Click here to download high resolution image

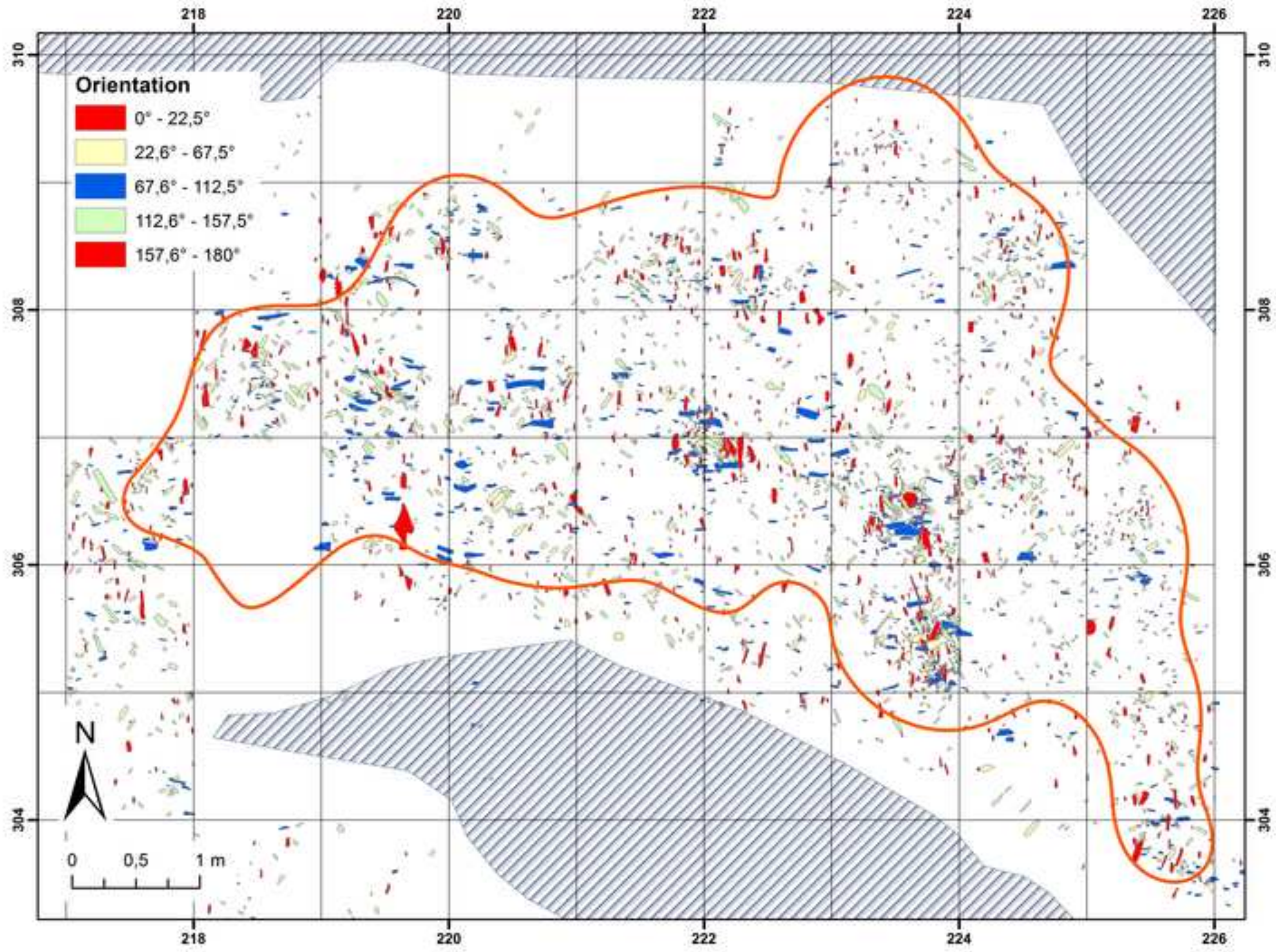




\section{NN2/2B Orientation}

\begin{tabular}{|c|c|c|c|}
\hline Square ID & Number of Observations & Mean Vector $(\mu)$ & $\begin{array}{c}\text { Orientation } \\
\text { Length of Mean Vector }(r)\end{array}$ \\
\hline $223 / 309$ & 173 & 178.83 & 0.202 \\
\hline $217 / 317$ & 2 & 24.25 & 0.663 \\
\hline $216 / 310$ & 25 & 100.255 & 0.326 \\
\hline $225 / 316$ & 35 & 26.306 & 0.056 \\
\hline $225 / 315$ & 73 & 30.922 & 0.295 \\
\hline $225 / 314$ & 92 & 174.186 & 0.219 \\
\hline $225 / 313$ & 70 & 159.228 & 0.284 \\
\hline $225 / 312$ & 109 & 144.813 & 0.226 \\
\hline $225 / 311$ & 26 & 51.248 & 0.152 \\
\hline $225 / 310$ & 28 & 54.72 & 0.153 \\
\hline $224 / 316$ & 36 & 140.907 & 0.399 \\
\hline $224 / 315$ & 70 & 96.051 & 0.244 \\
\hline $224 / 314$ & 56 & 82.127 & 0.374 \\
\hline $224 / 313$ & 87 & 148.119 & 0.033 \\
\hline $224 / 312$ & 5 & 23.1 & 0.763 \\
\hline $223 / 315$ & 10 & 32.298 & 0.129 \\
\hline $223 / 314$ & 9 & 80.96 & 0.328 \\
\hline $223 / 313$ & 5 & 135.319 & 0.714 \\
\hline $222 / 317$ & 33 & 89.987 & 0.068 \\
\hline $222 / 316$ & 13 & 133.877 & 0.491 \\
\hline $222 / 315$ & 2 & 147.5 & 0.423 \\
\hline $222 / 314$ & 11 & 66.243 & 0.383 \\
\hline $222 / 313$ & 2 & 150.5 & 0.996 \\
\hline $221 / 315$ & 8 & 146.691 & 0.291 \\
\hline $221 / 314$ & 1 & 23.6 & 1 \\
\hline 221/311 & 22 & 126.275 & 0.17 \\
\hline $221 / 310$ & 18 & 74.858 & 0.188 \\
\hline $220 / 315$ & 8 & 17.443 & 0.409 \\
\hline $220 / 314$ & 16 & 171.06 & 0.173 \\
\hline $220 / 313$ & 23 & 170.357 & 0.307 \\
\hline $220 / 312$ & 21 & 57.625 & 0.296 \\
\hline $220 / 311$ & 37 & 174.817 & 0.262 \\
\hline $220 / 310$ & 31 & 15.971 & 0.357 \\
\hline $219 / 317$ & 13 & 78.256 & 0.349 \\
\hline $219 / 316$ & 9 & 177.33 & 0.655 \\
\hline 219/315 & 19 & 163.871 & 0.231 \\
\hline $219 / 314$ & 33 & 139.34 & 0.591 \\
\hline $219 / 312$ & 13 & 123.072 & 0.329 \\
\hline $219 / 313$ & 80 & 92.619 & 0.265 \\
\hline $219 / 311$ & 42 & 145.448 & 0.363 \\
\hline 219/310 & 33 & 31.252 & 0.192 \\
\hline $218 / 317$ & 36 & 122.712 & 0.088 \\
\hline $218 / 316$ & 28 & 37.461 & 0.211 \\
\hline 218/315 & 33 & 145.182 & 0.225 \\
\hline
\end{tabular}




\section{Supplementary Information Figure 1}

Click here to download high resolution image

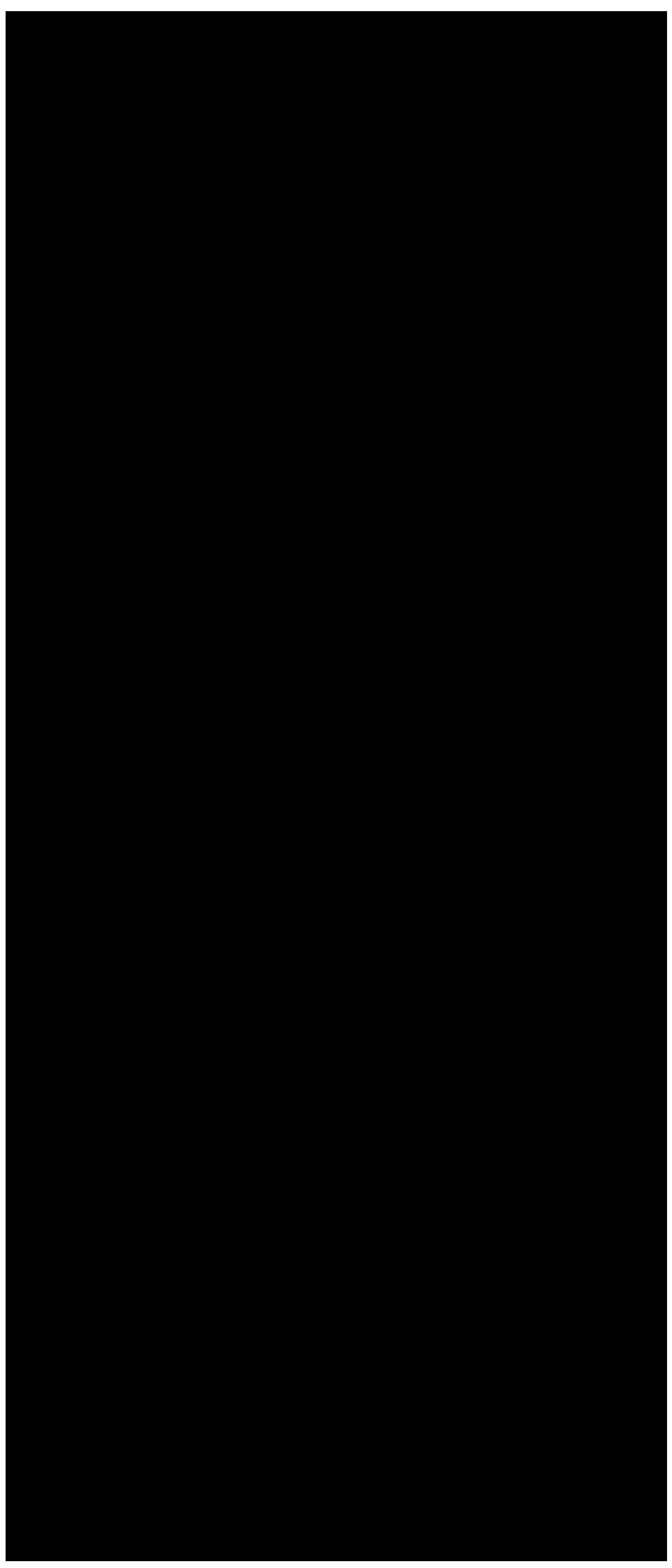


Click here to download high resolution image
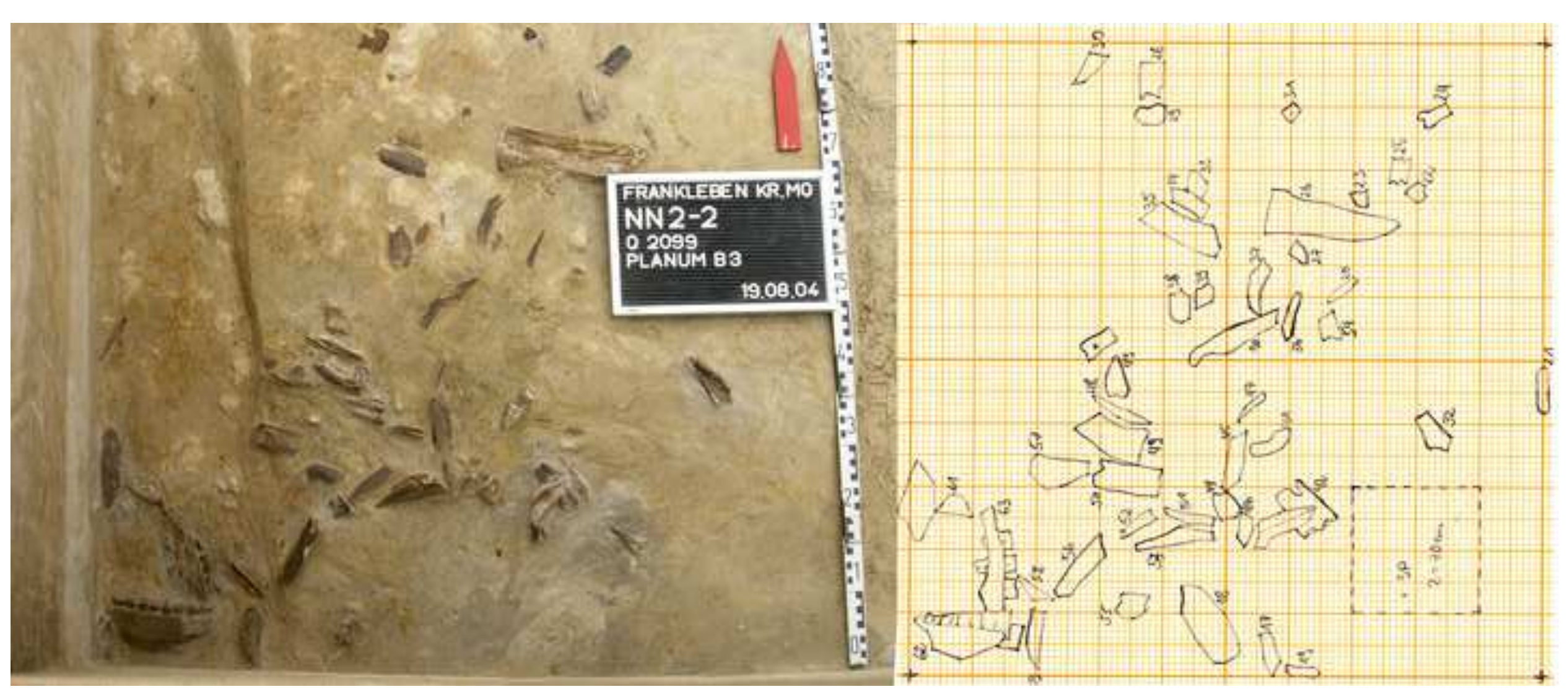


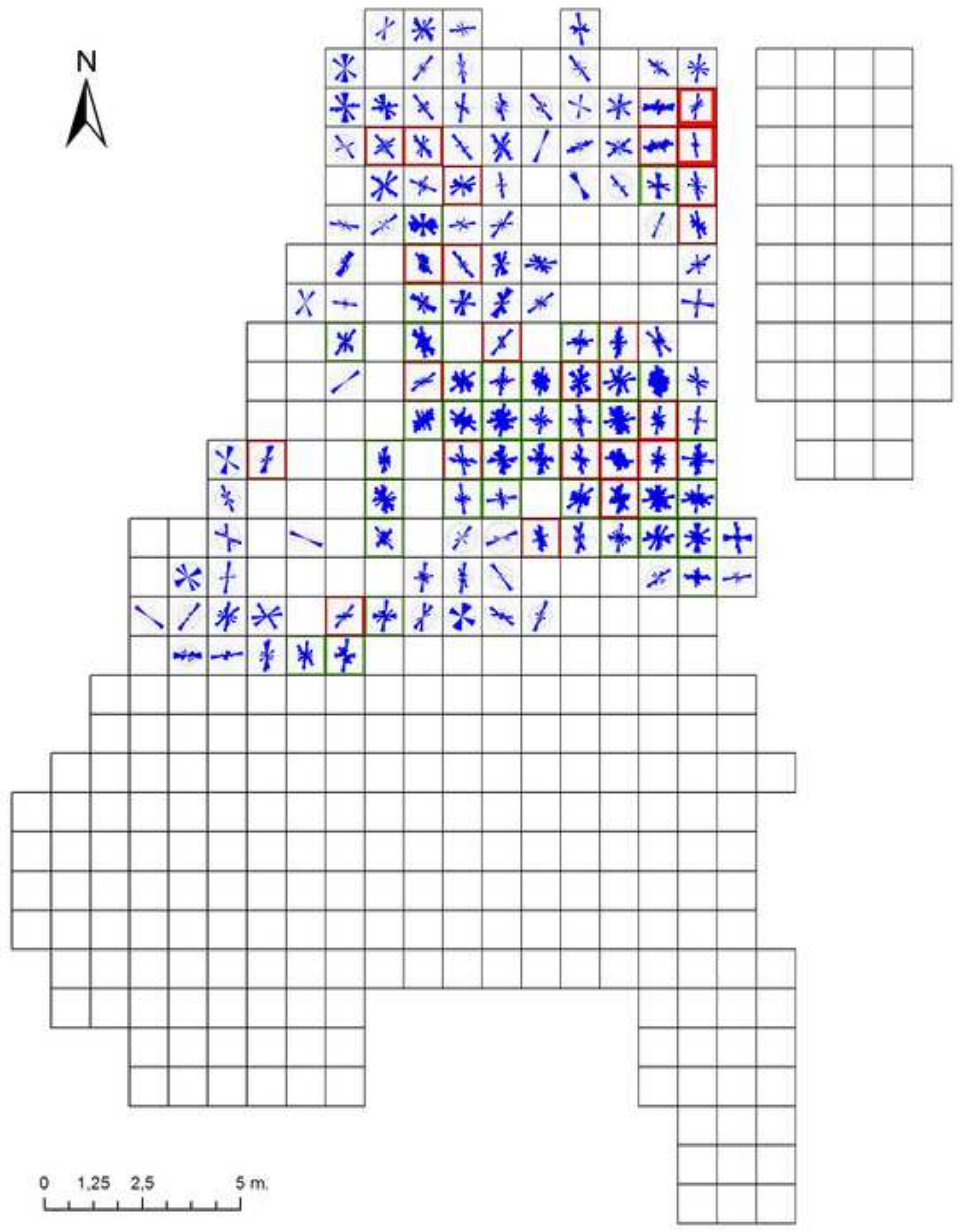




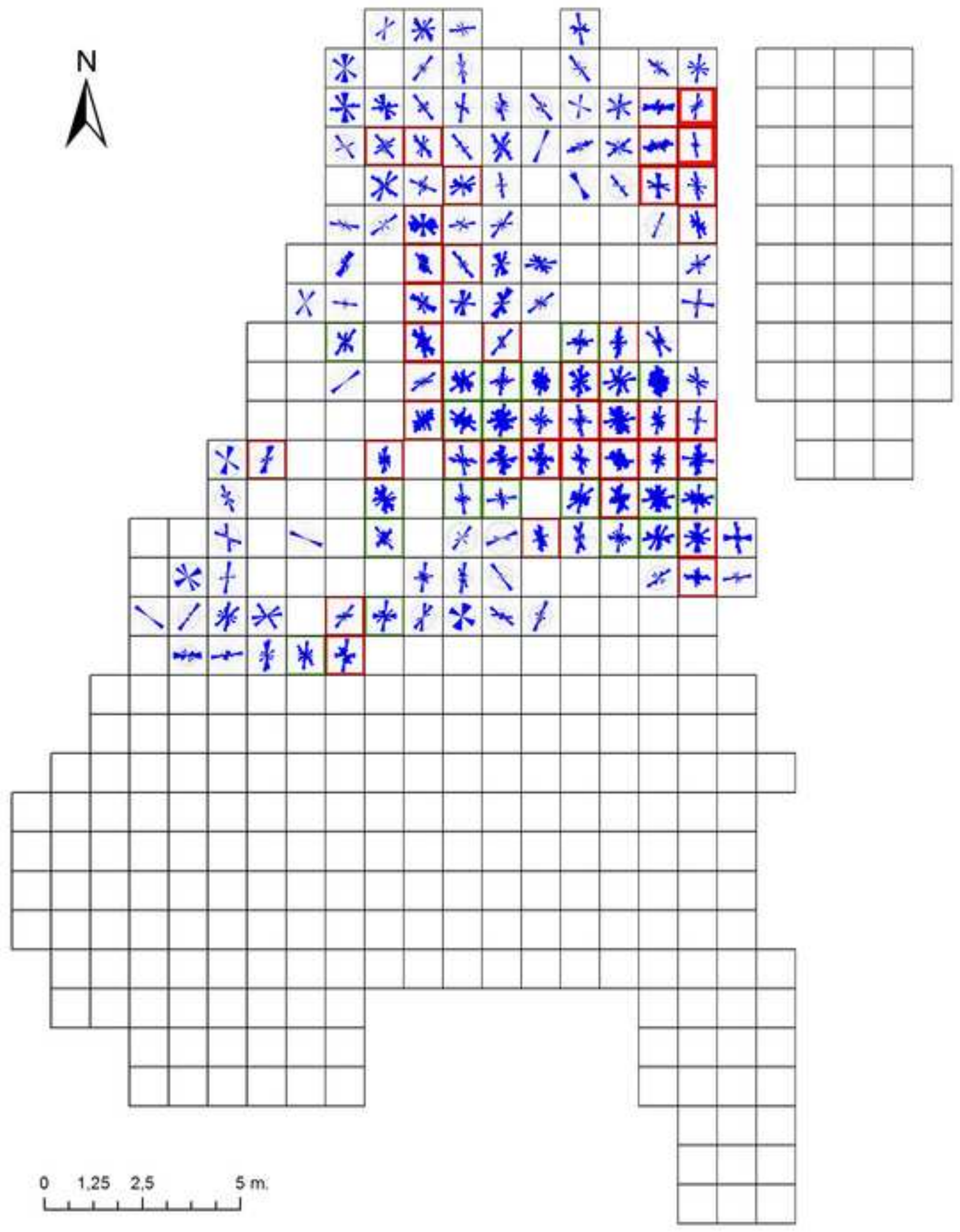


Supplementary Information Figure 5

Click here to download high resolution image

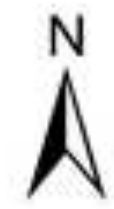

Non-uniform orient.

No
Yes
Yes Disturbance
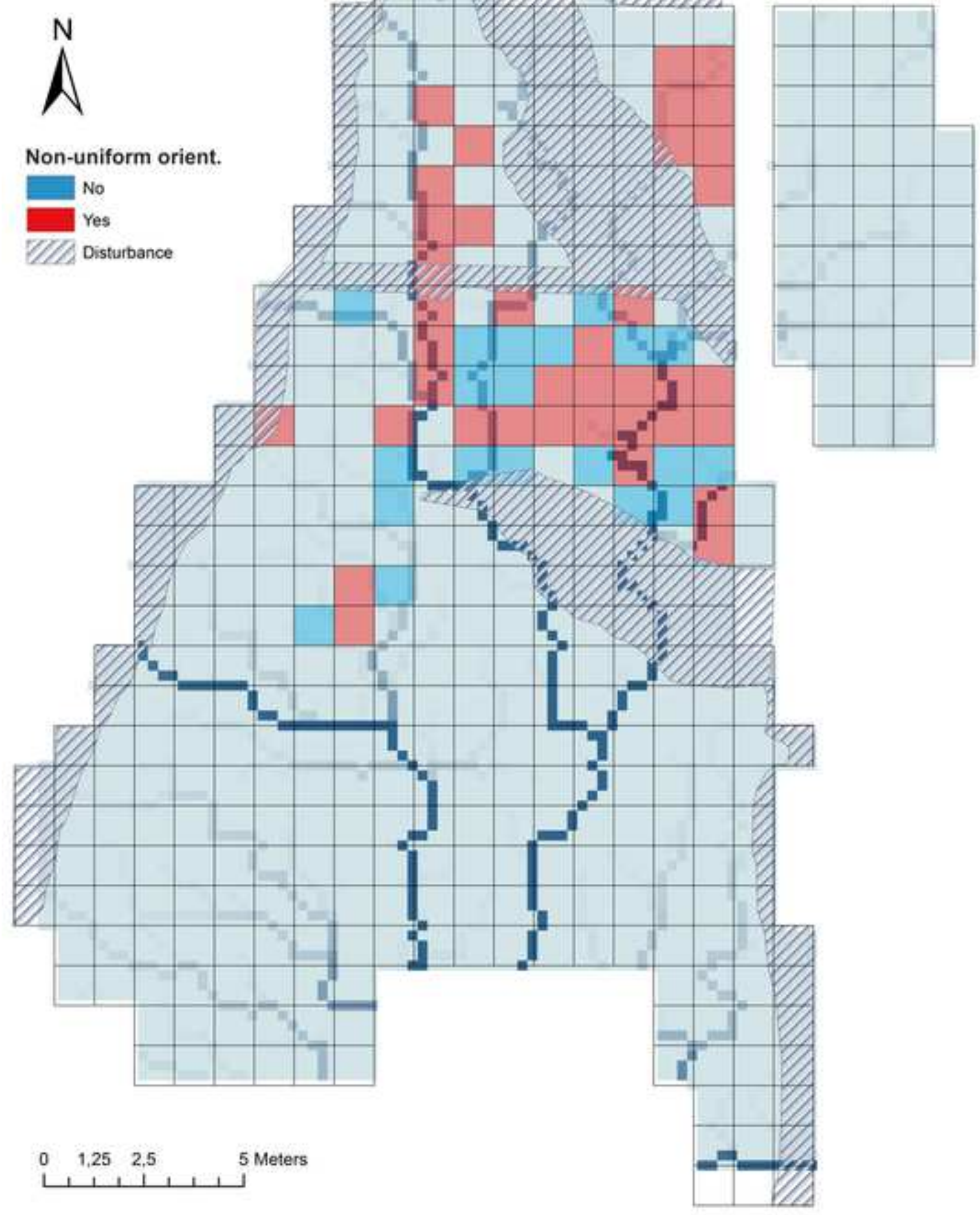
Supplementary Information Figure 6

Click here to download high resolution image

\section{Genus}

- Bor

- Bow/Rhino

- Cerv

- Eq

- Probos

- Herb

- indet.

Anat, region

- Auto

A Axial

- Cran

- Flat

* Lng

*t Ing/Axial

$X$ indet.
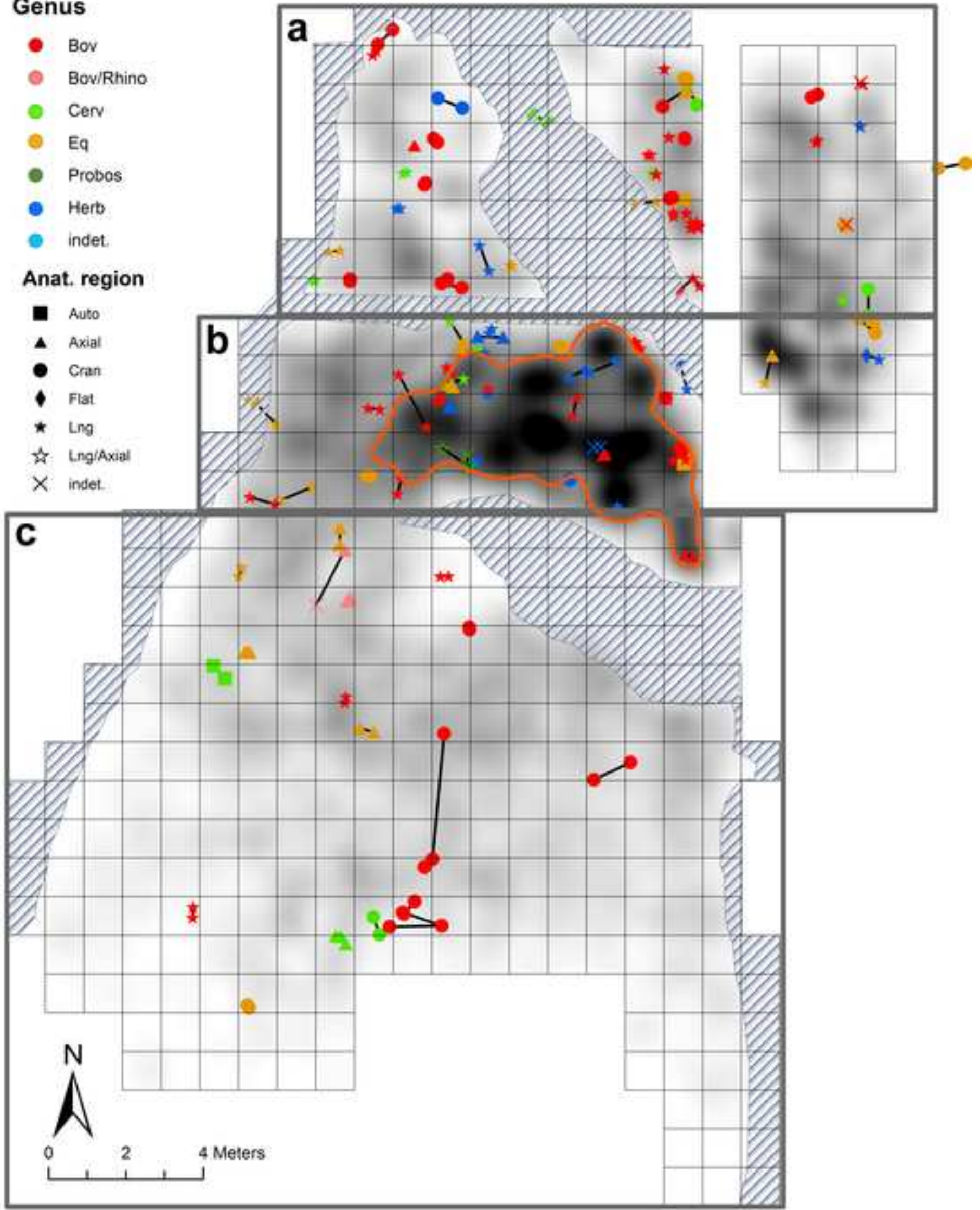
Supplementary Information Figure 7

Click here to download high resolution image

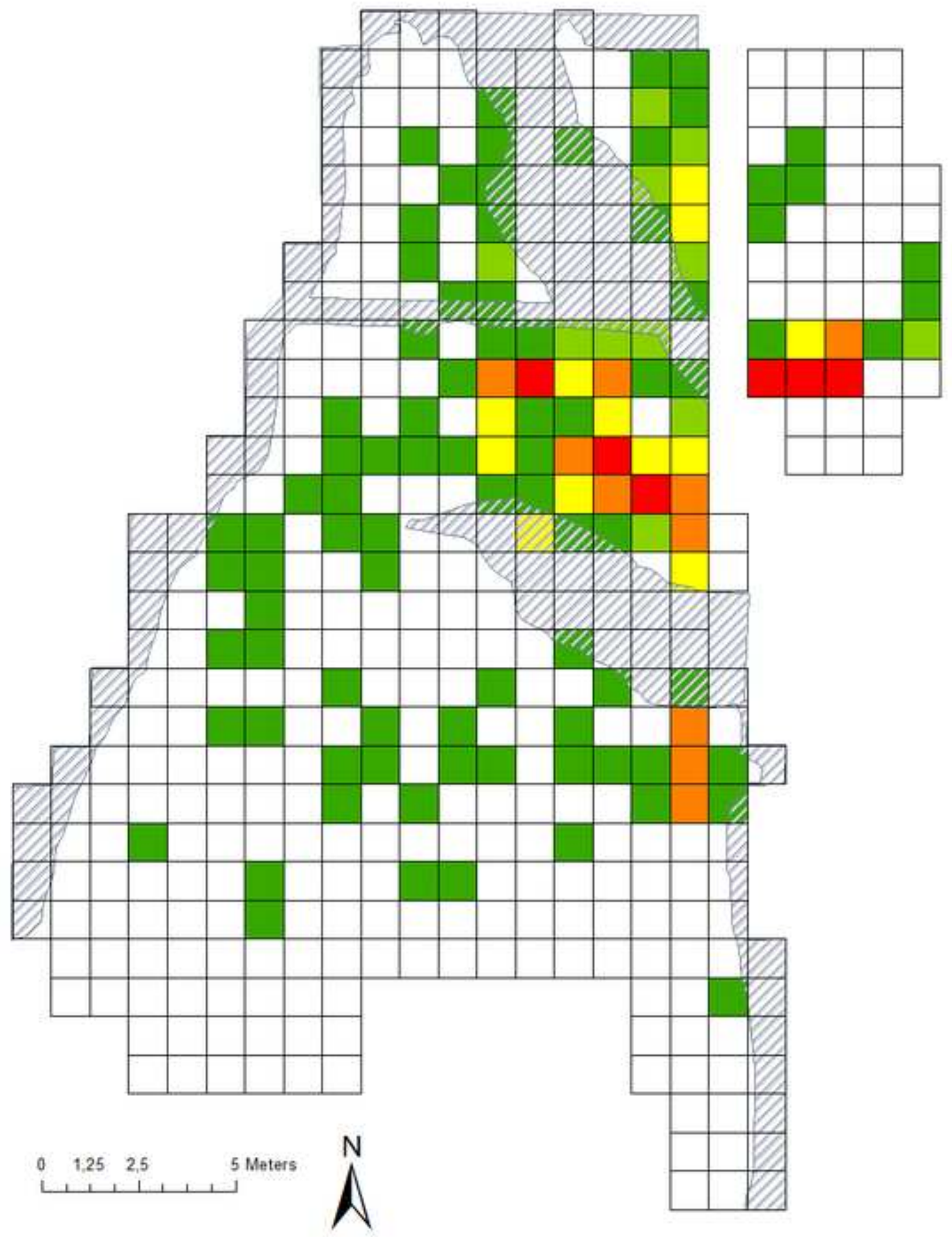

